\title{
Overexpression of Parkin in clear cell renal cell carcinoma decreases tumor aggressiveness by regulating CKS2 levels
}

\author{
LAURA KRISTIN ESSER $^{1}$, VITTORIO BRANCHI ${ }^{2}$, FARHAD SHAKERI $^{3-5}$, ADRIAN GEORG SIMON $^{1}$, \\ CARSTEN STEPHAN ${ }^{6}$, GLEN KRISTIANSEN ${ }^{1}$, ANDREAS BUNESS ${ }^{3-5}$, \\ HUBERT SCHORLE $^{7}$ and MARIETA IOANA TOMA ${ }^{1}$
}

\author{
${ }^{1}$ Institute of Pathology; ${ }^{2}$ Department of General, Visceral, Thoracic and Vascular Surgery, University Hospital Bonn; \\ ${ }^{3}$ Institute for Medical Biometry, Informatics and Epidemiology; ${ }^{4}$ Institute for Genomic Statistics and Bioinformatics; \\ ${ }^{5}$ Core Unit for Bioinformatics Analysis, Medical Faculty, University of Bonn, D-53127 Bonn; \\ ${ }^{6}$ Department of Urology, Charité-Universitätsmedizin Berlin, Corporate Member of Freie Universität Berlin and \\ Berlin Institute for Urologic Research, D-10117 Berlin; ${ }^{7}$ Institute of Pathology, Department of \\ Developmental Pathology, University Hospital Bonn, D-53127 Bonn, Germany
}

Received August 15, 2021; Accepted November 25, 2021

DOI: $10.3892 /$ ijo.2022.5310

\begin{abstract}
Low expression levels of the E3 ubiquitin-protein ligase Parkin (PARK2) are exhibited in several cancer entities, including clear cell renal cell carcinoma (ccRCC), and are associated with poor prognosis; however, PARK2 can also function as a tumor suppressor gene. The aim of the present study was to thoroughly investigate the effects of PARK2 overexpression in ccRCC cell lines and to determine its effects on malignancy by conducting functional assays such as cell cycle analysis, apoptosis analysis, migration and invasion assays. Furthermore, liquid chromatography-mass spectrometry was used to decipher potential targets of PARK2 that may influence the behavior of ccRCC tumor cells. In addition, ccRCC tumor tissues from a patient cohort were examined in tissue microarrays to find correlations between different clinical parameters. In the present study, it was demonstrated that the induction of PARK2 resulted in a less aggressive phenotype, as indicated by lower migration and invasion in ccRCC cell lines. Mass spectrometry revealed decreased levels of 29 proteins in cells with PARK2 overexpression, including CDC28 protein kinase regulatory subunit 2
\end{abstract}

Correspondence to: Dr Marieta Ioana Toma, Institute of Pathology, University Hospital Bonn, Venusberg Campus 1, D-53127 Bonn, Germany

E-mail: marieta.toma@ukbonn.de

Abbreviations: ccRCC, clear cell renal cell carcinoma; CKS2, CDC28 protein kinase regulatory subunit 2; FDR, false discovery rate; LC-MS, liquid chromatography-mass spectrometry; MFN2, mitofusin 2; OSBPL10, oxysterol-binding protein-like 10; PARK2, Parkin; PBS, phosphate-buffered saline; RCC, renal cell carcinoma; TMA, tissue microarray

Key words: ccRCC, PARK2, CKS2, E3 ubiquitin-protein ligase
(CKS2), which is highly expressed in numerous types of cancer. The link between the function of PARK2 as an E3 ubiquitin ligase and the low expression levels of CKS2 was investigated by mutating the catalytic domain of the PARK2 gene, and it was found that the effect of decreased migration was abolished in 786-O and RCC-MH ccRCC cell lines. CKS2 silencing decreased migratory ability of the cells. Furthermore, it was revealed that high CKS2 levels are associated with high tumor grading in patient samples and lower patient survival. In conclusion, the results from the present study indicated that PARK2 may signal via CKS2 to affect tumor behavior. In consequence, CKS2 may be a biomarker in ccRCC and may also serve as potential target for ccRCC therapy.

\section{Introduction}

Kidney cancer was the 16 th most common cancer in 2020 (1). In that year, 430,000 patients were diagnosed and $\sim 180,000$ people succumbed to this malignancy worldwide (1). Even though incidence numbers have been almost stable since 2008 and death rates are slightly decreasing, it accounted for $4.6 \%$ of all diagnosed cancer cases in 2020 (2). Men are twice as likely as women to be diagnosed, which might be explained by a lifestyle with higher risk factors, including smoking and obesity (3). The most common form of kidney cancer is renal cell carcinoma (RCC), which is again subdivided into several subtypes, such as clear cell (cc)RCC, papillary RCC and chromophobe RCC; of these subtypes, ccRCC is the most common, accounting for $75 \%$ of all cases (4). Survival rates for kidney cancer have increased steadily each year from 2000 to 2018 (2). The 5-year overall survival rate is $75 \%$, but numbers decrease drastically with higher staging; the 5-year survival rate for stages I and II is 93\%, it decreases to $70 \%$ at stage III and drops down to $13 \%$ at stage IV (3). The increase in the survival rate is likely due to increased routine use of sonography which leads to earlier detection of potential tumors and, thus, better treatment options. However, therapies 
for metastasized RCC remain scarce. RCC is largely resistant to conventional chemotherapy and radiation; therefore, the therapy of choice as of now is (partial) nephrectomy, targeted therapy and immunotherapy, or a combination of these treatments (3). The lack of symptoms, the aggressiveness of the disease (specifically at later stages) and the limitation of available therapies highlight the urgent need for valuable, targetable genes for potential new therapy approaches.

Expression of the Parkin (PARK2) gene was found to be downregulated in several cancer entities $(5,6)$. First described in autosomal recessive juvenile Parkinson's disease (7), evidence is growing that PARK2 also functions as a tumor suppressor gene. Several different mechanisms for its tumor suppressive function have been shown. For example, Ikeuchi et al (8) demonstrated that PARK2 is involved in cell cycle progression in colorectal cancer. Another study showed that PARK2 binds to microtubules and sensitizes breast cancer cells to drug-induced apoptosis (9). Liu et al (10) reported that PARK2 ubiquitinates hypoxia-inducible factor $1 \alpha$ inducing its degradation and, consequently, inhibiting migration and invasion of breast cancer cells. Furthermore, PARK2 may inhibit pyruvate kinase M2 activity, which suppresses glycolysis (11). PARK2 is also involved in mitophagy, which eliminates the accumulation of damaged mitochondria, mitochondrial DNA mutations and reactive oxygen species $(12,13)$. Despite investigations in other types of cancer, the contribution of PARK2 to the etiology of ccRCC tumorigenesis and the underlying mechanism remain unknown. In addition to its role as a tumor suppressor, the RING-finger-containing protein PARK2 can function as an E3 ubiquitin-protein ligase, which are proteins involved in the ubiquitination process that results in degradation of substrate proteins (14). Some substrate proteins of PARK2, such as hypoxia-inducible factor $1 \alpha$ and pyruvate kinase M2, have been described previously $(10,11)$; however, the mechanisms of PARK2 within the cell have not been completely deciphered.

The present study aimed to investigate the role of PARK2 in ccRCC tumorigenesis. However, as there are no commercially available ccRCC cell lines or primary ccRCC cell lines that expresses PARK2 to a sufficient level, ccRCC cell lines overexpressing PARK2 were generated and established to examine the role of PARK2 in ccRCC.

\section{Materials and methods}

Cell culture. 786-O and RCC-MH cells were maintained in RPMI-1640 (Thermo Fisher Scientific, Inc.) and 293T cells were maintained in DMEM + GlutaMAX ${ }^{\mathrm{TM}}$ (Thermo Fisher Scientific, Inc.). All media were supplemented with $10 \%$ fetal bovine serum (FBS; Thermo Fisher Scientific, Inc.,) and $1 \%$ penicillin/streptomycin (Thermo Fisher Scientific, Inc.). Cells were incubated at $37^{\circ} \mathrm{C}, 95 \%$ humidity and $5 \% \mathrm{CO}_{2}$. 786-O and $293 \mathrm{~T}$ cell lines were ordered from American Type Culture Collection, and RCC-MH cells were purchased from Cell Lines Service GmbH. 786-O cells were authenticated by multiplex human cell line authentication test (Multiplexion $\mathrm{GmbH}$ ). Cells were regularly passaged and checked for mycoplasma contamination. Primary ccRCC cells were cultivated as previously described (15). Briefly, small pieces of fresh tumor tissue $\left(1 \mathrm{~cm}^{3}\right)$ were obtained from 7 patients undergoing partial or complete nephrectomy between October and December 2017 in the Department of Urology of the University Hospital Bonn (Bonn, Germany) (mean age, 67 years; age range, 50-87 years). The tumors were classified according to UICC 2017 and the tumor grading was assessed according to ISUP 2016; clinicopathological characteristics are listed in Table I. The tissue was digested in pre-warmed RPMI-1640 medium (Thermo Fisher Scientific, Inc.) containing $200 \mathrm{U} / \mathrm{ml}$ collagenase type II (Thermo Fisher Scientific, Inc.), $100 \mathrm{U} / \mathrm{ml}$ hyaluronidase type V (Sigma-Aldrich; Merck KGaA) and $2 \%$ penicillin/streptomycin (Thermo Fisher Scientific, Inc.), and cultivated in a specific serum-reduced medium. The serum-reduced medium consisted of DMEM/F12 medium containing 5\% FBS (Thermo Fisher Scientific, Inc.), $1 \%$ penicillin/streptomycin (Thermo Fisher Scientific, Inc.), 10 ng/ml hrEGF (R\&D Systems, Inc.), 10 ng/ml FGF-basic (PeproTech, Inc.), 1X B27 supplement (Gibco; Thermo Fisher Scientific, Inc.), 1X Lipid Mixture 1 (Sigma-Aldrich; Merck KGaA), 1 mM N-Acetyl-Cysteine (Acros Organics; Thermo Fisher Scientific, Inc.), 4 mM L-Glutamine (Thermo Fisher Scientific, Inc.), 1X MEM non-essential amino acids (Thermo Fisher Scientific, Inc.) and $10 \mathrm{~mm}$ HEPES (Cytiva) (15). The cultivation of the primary tumor cell cultures was approved by the Ethics Committee of the University Hospital Bonn (EK 219/17) and all patients provided written informed consent for use in future research.

Plasmid cloning. PARK2 and PARK2-C431S lentiviral plasmids were generated by sub-cloning the human wild-type (from plasmid pRK5-HA-Parkin; cat. no. 17613; Addgene, Inc.) or the catalytically inactive C431S mutant PARK2 (from pEGFP-parkin C431S; cat. no. 45877; Addgene, Inc.) into the restriction enzyme sites FastDigest EcoRI (Thermo Fisher Scientific, Inc.) and FastDigest BamHI (Thermo Fisher Scientific, Inc.) of plasmid pLVX-EF1 $\alpha$-IRES-mCherry (Takara Bio USA, Inc.).

Lentiviral production and cell transduction. Lentiviral particles were produced by co-transfecting $293 \mathrm{~T}$ cells with the lentiviral backbone plasmid of interest, aforementioned, the packaging plasmid psPAX2 and the envelope plasmid pMD2 (both plasmids were gifts from Prof. Dr. Hubert Schorle, Department for Developmental Biology, University Hospital Bonn, Germany) using Polyethylenimine (Merck KGaA) for $48 \mathrm{~h}$ at $37^{\circ} \mathrm{C}$. The viral supernatant was subsequently collected and passed through a $0.4 \mu \mathrm{m}$ filter. Transduction of cells was performed by adding the collected viral particles with polybrene $(10 \mu \mathrm{g} / \mathrm{ml})$ on top of the cells of interest (786-O and RCC-MH), which were plated and incubated 1 day before so that they reached $70 \%$ confluence at the day of transduction. At $24 \mathrm{~h}$ after transduction at $37^{\circ} \mathrm{C}$, the viral particle-containing medium was aspirated and fresh regular growth medium was added. The following plasmids were used for lentiviral transfection: pLVX-EF1 $\alpha$-IRES-mCherry for empty vector (EV), plasmid pLVX-EF1 $\alpha$-PARK2-IRES-mCherry for PARK2 overexpression (PARK2), and plasmid pLVX-EF1 $\alpha$-PARK2 (C431S)-IRES-mCherry for the catalytically inactive PARK2 mutant (C431S). Following successful transduction and expansion of the cell lines for one week, the mCherry-positive clones were sorted by flow cytometry to select only the stable clones. 
Table I. Clinicopathological data of the patients from which the primary clear cell renal cell carcinoma cultures were obtained.

\begin{tabular}{lc}
\hline Clinicopathological characteristic & Number (\%) \\
\hline Sex & \\
Male & $4(57.1)$ \\
Female & $3(42.9)$ \\
Age, years & \\
Mean & 67 \\
pT stage & \\
T1 & $4(57.1)$ \\
T2 & $3(42.9)$ \\
Grade & \\
G1 & $1(14.2)$ \\
G2 & $3(42.9)$ \\
G3 & $3(42.9)$ \\
\hline
\end{tabular}

RNA extraction. RNA from cultured cells was extracted with the Universal RNA Kit (Roboklon $\mathrm{GmbH}$ ) according to the manufacturer's instructions. Briefly, cells were lysed in the culture dish, transferred to a homogenization spin-column and centrifuged at $11,000 \mathrm{x}$ g. Cold ethanol $(100 \%)$ was added, the solution was mixed and applied to the RNA binding spin column. The column was washed three times with the washing reagent supplied by the manufacturer, and an on-column DNase digestion step was performed between the washing steps. RNA was eluted with RNase-free water, and the concentration was quantified using a NanoDrop system (NanoDrop; Thermo Fisher Scientific, Inc.).

RNA from tumor and matched non-neoplastic material from 63 patients undergoing partial or radical nephrectomy for ccRCC between January 2008 and August 2016 in the Department of Urology, University Hospital Bonn was extracted with the aforementioned Universal RNA Kit. The analysis was approved by the Ethics Committee of the University Hospital Bonn (EK 219/17), and the patients provided written informed consent.

Reverse transcription quantitative PCR (RT-qPCR) analysis. Total RNA was extracted as aforementioned, and reverse transcribed with SuperScript ${ }^{\mathrm{TM}}$ II Reverse Transcriptase (Invitrogen; Thermo Fisher Scientific, Inc.) according to the manufacturer's instructions. In brief, oligo(dT) primers $(500 \mu \mathrm{g} / \mathrm{ml}), \mathrm{dNTP} \operatorname{mix}(10 \mathrm{mM}$ each), RNA ( $1 \mu \mathrm{g})$ and $\mathrm{ddH}_{2} \mathrm{O}$ were mixed, heated to $65^{\circ} \mathrm{C}$ for $5 \mathrm{~min}$ and quickly chilled on ice. Subsequently, 5X first-strand buffer, 0.1 M DTT and RNaseOUT (40 U/ $/ \mu$ ) were added, mixed and incubated at $42^{\circ} \mathrm{C}$ for $2 \mathrm{~min}$. SuperScript II reverse transcriptase (200 U) were added, incubated at $42^{\circ} \mathrm{C}$ for $50 \mathrm{~min}$ and inactivated at $70^{\circ} \mathrm{C}$ for $15 \mathrm{~min}$. For qPCR analysis, SYBR green (Bio-Rad Laboratories Inc.), target-specific primers (Table SI) and $5 \mathrm{ng}$ cDNA template were used. The samples were analyzed on a ViiA 7 Real-Time-PCR system (Thermo Fisher Scientific, Inc.) using the following conditions: Hold stage at $50^{\circ} \mathrm{C}$ for $2 \mathrm{~min}$; initial denaturation at $95^{\circ} \mathrm{C}$ for $10 \mathrm{~min}$; followed by 40 cycles of $95^{\circ} \mathrm{C}$ for $15 \mathrm{sec}, 63^{\circ} \mathrm{C}$ for $2 \mathrm{sec}$ and $60^{\circ} \mathrm{C}$ for $1 \mathrm{~min}$; melt curve analysis at $95^{\circ} \mathrm{C}$ for $15 \mathrm{sec}, 60^{\circ} \mathrm{C}$ for $1 \mathrm{~min}$ and $95^{\circ} \mathrm{C}$ for $15 \mathrm{sec}$. Data were normalized to the housekeeping genes TATA-box binding protein and $\beta$-actin, and displayed in relation to the wild-type cells or non-malignant tissue using the $2^{-\Delta \Delta \mathrm{Cq}}$ method (16).

3' mRNA sequencing. RNA was extracted from 786-O cells using the aforementioned Universal RNA Kit. Samples were then processed by the NGS Core Facility of the University Hospital Bonn. RNA quality was accessed by a TapeStation 4200 (Agilent Technologies, Inc.) automated electrophoresis system. The library was prepared using the QuantSeq 3'mRNA Seq Library Kit FWD (Lexogen $\mathrm{GmbH}$ ) according to the manufacturer's instructions and subsequently analyzed on a HiSeq 2500 v4 sequencer (Illumina, Inc.) in high output mode (1x50 bp single reads). For analysis, raw single-read sequencing results were mapped to the human genome (GRCh38) with hisat2-2.1.0 (17). Next, the mapped reads were processed using samtools (18) and featureCounts (19) to quantify reads. Read counts were further processed in the $\mathrm{R}$ environment version 4.0 (20) and statistically analyzed with the Bioconductor software package DESeq2 (21). Differentially expressed genes were calculated for each of the groups by applying multiple testing corrections including Bonferroni correction method and false discovery rates (FDR). An FDR cutoff of 0.05 was accepted as significant). $\log 2$ fold change shrinkage was calculated using the Bioconductor package apeglm (22). The principal component analysis plot was generated using ggplot2 (23).

Immunoblotting. Cells were lysed with RIPA buffer (MilliporeSigma) supplemented with Halt ${ }^{\mathrm{TM}}$ Protease and Phosphatase Inhibitor Cocktail (Thermo Fisher Scientific, Inc.). Lysates were kept on ice for $30 \mathrm{~min}$ and centrifuged at $14,000 \mathrm{x}$ g for $20 \mathrm{~min}$ at $4^{\circ} \mathrm{C}$. Protein concentration was measured with the Pierce ${ }^{\mathrm{TM}}$ BCA Protein Assay Kit (Thermo Fisher Scientific, Inc.) according to the manufacturer's instructions. Immunoblotting was performed according to standard protocols. In brief, $20 \mu \mathrm{g}$ of protein were separated by SDS-PAGE on $12 \%$ gels, transferred to a PVDF membrane, blocked with $5 \%$ non-fat dried milk powder (PanReac AppliChem $\mathrm{GmbH}$ ) in Tris-buffered saline with $0.1 \%$ Tween (TBST) for $1 \mathrm{~h}$ at RT, and then incubated with the primary antibody overnight at $4^{\circ} \mathrm{C}$. The next day, the membrane was washed three times with TBST, incubated with the adequate secondary antibody for $1 \mathrm{~h}$ at RT, developed with SuperSignal $^{\mathrm{TM}}$ West Pico PLUS Chemiluminescent Substrate (Thermo Fisher Scientific, Inc.) and images were captured using a Chemi Doc MP Gel Imaging System (Bio-Rad Laboratories, Inc.). Densities were quantified using the Fiji package for ImageJ (National Institutes of Health). The following antibodies were used for immunoblotting (all from Santa Cruz Biotechnology, Inc.): Anti-PARK2 (1:500; cat no. sc-32282, clone PRK8); anti- $\beta$-actin (1:500; cat. no. sc-47778,

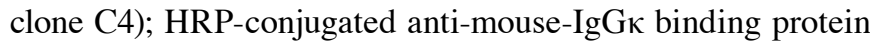
secondary antibody (1:5,000; cat. no. sc-516102).

Flow cytometry. For cell cycle analysis, 786-O cells were harvested at a confluence of $80 \%$ by trypsinization, washed in phosphate-buffered saline (PBS) and ice-cold 70\% ethanol 
was added dropwise, and the cells were fixed in ethanol at $4^{\circ} \mathrm{C}$ overnight. The cells were then centrifuged at $100 \mathrm{x} \mathrm{g}$, at $4^{\circ} \mathrm{C}$ for $5 \mathrm{~min}$ and stained with DAPI $+0.1 \%$ Triton X-100 $(10 \mu \mathrm{g} / \mathrm{ml})$ and incubated for $20 \mathrm{~min}$ in the dark before being analyzed on a BD LSRFortessa cell analyzer (BD Biosciences).

For apoptosis analysis, cells were stained using the Annexin V-FITC Apoptosis Staining/Detection Kit (cat. no. ab14085; Abcam). Briefly, cells were counted and $1 \times 10^{5}$ cells were resuspended per $500 \mu 1 \mathrm{lX}$ Annexin V Binding Buffer and incubated with Annexin V-FITC for $15 \mathrm{~min}$ at room temperature; to quantify dead cells, DAPI staining was included in this incubation. Cells were analyzed on a BD LSR Fortessa (BD Biosciences).

Transwell Boyden chamber migration and invasion assays. Cells were starved overnight in low-serum medium $(0.2 \% \mathrm{FBS})$. The next day, cells $\left(3 \times 10^{4}\right.$ cells/well $)$ were plated in 24-well plates in $200 \mu \mathrm{l}$ low-serum medium on top of a FluoroBlok $^{\mathrm{TM}}$ Cell Culture Insert (Corning, Inc.). A total of $600 \mu \mathrm{l}$ complete growth medium (10\% FBS) was placed into the lower chamber. Cells were incubated at $37^{\circ} \mathrm{C}$ in $5 \% \mathrm{CO}_{2}$ for $16 \mathrm{~h}$. After incubation, the medium was aspirated and the inserts were placed in $100 \%$ methanol with DAPI $(2 \mu \mathrm{g} / \mathrm{ml})$ for $15 \mathrm{~min}$ at room temperature. Next, the DAPI-methanol suspension was removed, cells were washed twice with PBS and images were captured from five independent fields using a fluorescence microscope. For the invasion assay, the procedure was slightly changed by coating the inserts with $0.25 \mathrm{mg} / \mathrm{ml}$ Matrigel (Corning, Inc.). The coated plates were incubated at $37^{\circ} \mathrm{C}$ for $3 \mathrm{~h}$ and left to dry under the hood before plating the cells. The cells were then incubated for $48 \mathrm{~h}$ and analyzed as aforementioned. Invasion assays were performed according to standard protocols; to calculate the percentage of invasive cells, cells were plated side-by-side for migration and invasion, according to the manufacturers protocol.

CDC28 protein kinase regulatory subunit 2 (CKS2) small interfering RNA (siRNA) knockdown. Cells were transfected with 100 pmol CKS2 siRNA (FlexiTube; Qiagen $\mathrm{GmbH}$ ) or AllStars Negative Control siRNA (scramble; cat. no. 1027280, proprietary sequence; Qiagen $\mathrm{GmbH}$ ). The CKS2 siRNA contained four different CKS2-specific target sequences: 5'-AAGTTTGTATGTTGCATTTAA-3', 5'-CTCAGTTAAA TGCAACTGCAA-3', 5'-TAGGTTACTGTAAGATGTTTA-3' and 5'-CTGTAAGATGTTTAAGATAAA-3'. For transfections, Lipofectamine 2000 ${ }^{\mathrm{TM}}$ (Invitrogen; Thermo Fisher Scientific, Inc.) and Opti-MEM (Thermo Fisher Scientific, Inc.) were mixed together and incubated for $5 \mathrm{~min}$ at room temperature, then added to the siRNA and incubated for $20 \mathrm{~min}$ at room temperature. Next, the mixture was added to the cells and incubated for $4 \mathrm{~h}$, after which the medium was replaced by regular growth medium, and the cells were incubated for a further 24 to $48 \mathrm{~h}$ until used for subsequent experiments.

Peptide preparation. Total protein was harvested from cells by adding the following buffer: $8 \mathrm{M}$ Urea, 4\% CHAPS, $1 \%$ DTT and $1 \%$ Protease Inhibitor Cocktail. Cells were scraped, incubated on ice for $30 \mathrm{~min}$ and subsequently sonicated for $5 \mathrm{~min}$ at $30 \mathrm{sec}$ intervals in an ultrasonic ice bath. Afterward, samples were placed on ice for $5 \mathrm{~min}$ and centrifuged at $4^{\circ} \mathrm{C}$ for
$20 \mathrm{~min}$ at $13,000 \mathrm{x}$ g. Cell lysates were subjected to in-solution preparation of peptides on centrifugal filter units modified from previous studies (24-27). A total of $30 \mu \mathrm{g}$ protein was loaded onto centrifugal filter units with a $10 \mathrm{kDa}$ cutoff modified polyethersulfone membrane (Pall Filtersystems $\mathrm{GmbH}$ ) and reduced with $20 \mathrm{mM}$ DTT at $55^{\circ} \mathrm{C}$ for $30 \mathrm{~min}$. Alkylation of thiol groups was done with $40 \mathrm{mM}$ acrylamide for $30 \mathrm{~min}$ at room temperature. Following a buffer exchange, $250 \mathrm{ng}$ trypsin was added in $20 \mathrm{mM}$ triethylammonium bicarbonate (TEAB), $0.5 \%$ sodium deoxycholate (SDC) in a total volume of $50 \mu \mathrm{l}$. Digestion proceeded for $10 \mathrm{~h}$ at $37^{\circ} \mathrm{C}$. Peptides were collected by centrifugation at $10,000 \mathrm{x} \mathrm{g}$ at room temperature for $5 \mathrm{~min}$ and SDC was precipitated with trifluoroacetic acid (2\% final). The remaining SDC was removed by phase transfer with equal volume of ethyl acetate. Peptides were dried in a vacuum concentrator, redissolved in $20 \mathrm{mM}$ TEAB and labeled with isobaric TMT11plex reagents (Thermo Fisher Scientific, Inc.). Redissolved and pooled peptides were desalted on Oasis HLB cartridges (Waters $\mathrm{GmbH}$ ). Eluates containing $70 \%$ acetonitrile, $0.1 \%$ formic acid (FA) were dried and fractionated to 12 fractions by isoelectric point with an Offgel fractionator (Agilent Technologies Deutschland $\mathrm{GmbH})$. Peptide fractions were dried and stored at $-20^{\circ} \mathrm{C}$.

Liquid chromatography mass spectrometry (LC-MS) measurements. Peptide separation was performed on a Dionex Ultimate 3000 RSLCnano HPLC system (Dionex; Thermo Fisher Scientific, Inc.). The autosampler was operated in $\mu$ l-pickup mode. Peptides were dissolved in $0.1 \%$ FA (solvent A). A total of $1 \mu \mathrm{g}$ peptides (nominal) were injected onto a C18 analytical column (300 mm length, $75 \mu \mathrm{m}$ inner diameter; ReproSil-Pur 120 C18-AQ, $1.9 \mu \mathrm{m}$ (Dr. Maisch HPLC GmbH). Peptides were separated during a linear gradient from 2 to $35 \%$ solvent B $(90 \%$ acetonitrile, $0.1 \% \mathrm{FA}$ ) within $120 \mathrm{~min}$ at $300 \mathrm{nl} / \mathrm{min}$. The nano HPLC was coupled online to an Orbitrap Fusion Lumos MS (Thermo Fisher Scientific, Inc.) in positive ionization mode. Peptide ions between 330 and 1,500 m/z were scanned in the Orbitrap detector every $3 \mathrm{sec}$ with a resolution of $1.2 \times 10^{5}$ (maximum fill time $50 \mathrm{msec}$; automatic gain control target $\left.4 \times 10^{5}\right)$. Polysiloxane $(445.12002 \mathrm{~m} / \mathrm{z})$ was used for internal calibration (typical mass error $\leq 1.5 \mathrm{ppm}$ ). In a top-speed method peptides were subjected to collision-induced dissociation (CID) for identification (CID, 0.7 Da isolation; threshold intensity 5,000; normalized energy 35\%) and fragments analyzed in the linear ion trap with target $1 \times 10^{4}$ and maximum fill time $35 \mathrm{msec}$ (turbo mode). Fragmented peptide ions were excluded from repeat analysis for $25 \mathrm{sec}$. The top eight fragment ions were chosen for synchronous precursor selection and fragmented with higher energy CID (1.4 Da isolation; 65\% collision energy) for detection of reporter ions in the Orbitrap analyzer (resolution 50,000; maximum fill time 86 msec; target $1 \times 10^{5}$ ).

Proteomics data analysis. Statistical analyses of the peptide-spectrum match (PSM) level data were carried out in $\mathrm{R}$ environment ( $\mathrm{R}$ version 4.0) (20) using an in-house developed workflow. To start, one sample from each of the 786-O $\mathrm{O}^{\text {PARK2}}$ and 786-O wild-type groups were removed owing to an extreme amount of missing values. These were 
corresponding to tandem mass tag (TMT) channels $127 \mathrm{~N}$ and 128C (Fig. S1). Non-unique peptides and single-shot proteins [(proteins identified)/(quantified by only one peptide)] were filtered out prior to the statistical analysis. From all available fractions, only those with the least number of missing values per PSM and across all TMT channels were selected. In cases in which there were still more than one fraction available per PSM, the one with the highest average intensity across all channels was used. After the filtering procedure, the PSM-level data were variance-stabilized and transformed using the Bioconductor vsn package (28) and then aggregated to protein-level abundances by applying the Tukey's median polish method. The statistical analysis was performed using the R package limma (29). For each statistical contrast the resulting P-values were adjusted for multiple testing and the FDR were calculated by the Benjamini-Hochberg method. Proteins of interest for further analysis were selected using $\mid \log _{2} \mathrm{FCl}>1$.

Patient data. For the confirmation studies, tissue microarrays containing formalin-fixed (4\% buffered formalin fixation for $24 \mathrm{~h}$ at room temperature), paraffin-embedded material from 262 patients who underwent partial or radical nephrectomy between October 1992 and December 2004 for renal tumors in the Department of Urology, Charité University Medicine Berlin (Berlin, Germany) were included in the study (EA1/134/12; retrospective use of the patient data from Charite University Medicine Berlin). The studies were approved by the Ethics Committee of the University Hospital Bonn (EK 233/20). The mean of the age of the patients included in the TMAs was $60.8 \pm 9.573$ (range, 30-86 years); the median of the follow-up was 102.5 months (range 0-177). The clinicopathological characteristics of the patients are summarized in Table II. The material used for primary cell cultures and RT-qPCR was obtained from patients with ccRCC who underwent partial or radical nephrectomy between January 2008 and December 2017 in the Department of Urology, University Hospital Bonn; the patients provided written informed consent for use in future research at the time of tissue collection, and the study was approved by the Ethics Committee of the University Hospital Bonn (EK 219/17).

Tissue microarray (TMA). Briefly, the aforementioned formalin-fixed, paraffin-embedded tissues from representative areas of renal carcinoma and non-neoplastic tissues were used to construct the TMA. For each patient, two tumor and two normal tissue spots (diameter $1 \mathrm{~mm}$ ) were punched and transferred in the TMA paraffin block; $2-\mu \mathrm{m}$ sections from each TMA were cut and mounted on SuperFrost slides (Menzel Gläser; Thermo Fisher Scientific, Inc.). After deparaffinization with xylene and gradual rehydration in descending series of ethanol, antigen retrieval was performed [20 minutes in Cell Conditioning 1 ( $\mathrm{pH}$ 8); Roche Diagnostics]. PARK2 staining was performed on a Ventana BenchMark Ultra Autostainer (Roche Diagnostics) using an anti-PARK2 antibody (1:50; cat. no. sc-32282, clone PRK8; Santa Cruz Biotechnology, Inc.). The staining for CKS2 was performed manually using a CKS2 antibody (1:75; cat.no. ab155078, clone EPR7946(2); Abcam) incubated overnight at $4^{\circ} \mathrm{C}$. The detection was performed using an anti-rabbit
Table II. Clinicopathological data of the patients included in the TMAs.

\begin{tabular}{lr} 
Clinicopathological characteristic & Number \\
\hline Sex & \\
Male & 168 \\
Female & 94 \\
pT stage & \\
T1 & 153 \\
T2 & 18 \\
T3 & 88 \\
T4 & 3 \\
Grading & \\
G1 & 48 \\
G2 & 144 \\
G3 & 49 \\
G4 & 21
\end{tabular}

secondary antibody [Dako EnVision HRP-labeled polymer, ready-to-use (cat. no. K4003); Dako; Agilent Technologies, Inc.], and 3,3'-diaminobenzidine (DAB) chromogen (DAKO liquid $\mathrm{DAB}^{+}$substrate chromogen system; cat. no. K3468; Dako; Agilent Technologies, Inc.) was used for immunohistochemical staining. The slides were counterstained with hematoxylin for $30 \mathrm{sec}$ at room temperature and mounted. The immunohistochemical staining was evaluated under an Olympus BX50 light microscope (Olympus Corporation) blind to clinical outcome, clinical and pathological stage. Staining intensities were graded separately for cytoplasm and nucleus of tumor cells or non-neoplastic tubular cells (Fig. 1). A four-tier grading system was used, as follow: 0, negative; 1 , weakly positive; 2 , moderately positive; and 3 , strongly positive. PARK2 showed cytoplasmic staining, and after assessing the staining intensity, patients were separated into two groups: low PARK 2 expression (cases with grade 0 and 1 staining) and high PARK2 expression (cases with grade 2 and 3 PARK2 expression). CKS2 showed a cytoplasmic and a nuclear staining, with similar intensity, and separated into two groups: low CKS2 expression (grade 1 and 2 expression, similar to the non-neoplastic tissue) and high CKS2 expression (grade 3). No negative tumor cases were noticed.

Statistical analysis. Data were analyzed using GraphPad Prism version 8.2.0 (GraphPad Software, Inc.) or within the R environment version 4.0 (20) Wilcoxon signed-rank test was performed for paired samples. For multiple comparisons, Kruskal-Wallis test was performed to determine significance followed by Dunn's post hoc test. The Kaplan-Meier plots (followed by log-rank test), Cox proportional hazards regression model, and Pearson's and Spearman's correlation analyses were generated with the R packages survminer (30), survival (30) and ggplot2 (23). Data are presented as the mean \pm SEM. P-value $<0.05$ was considered to indicate a statistically significant difference. 

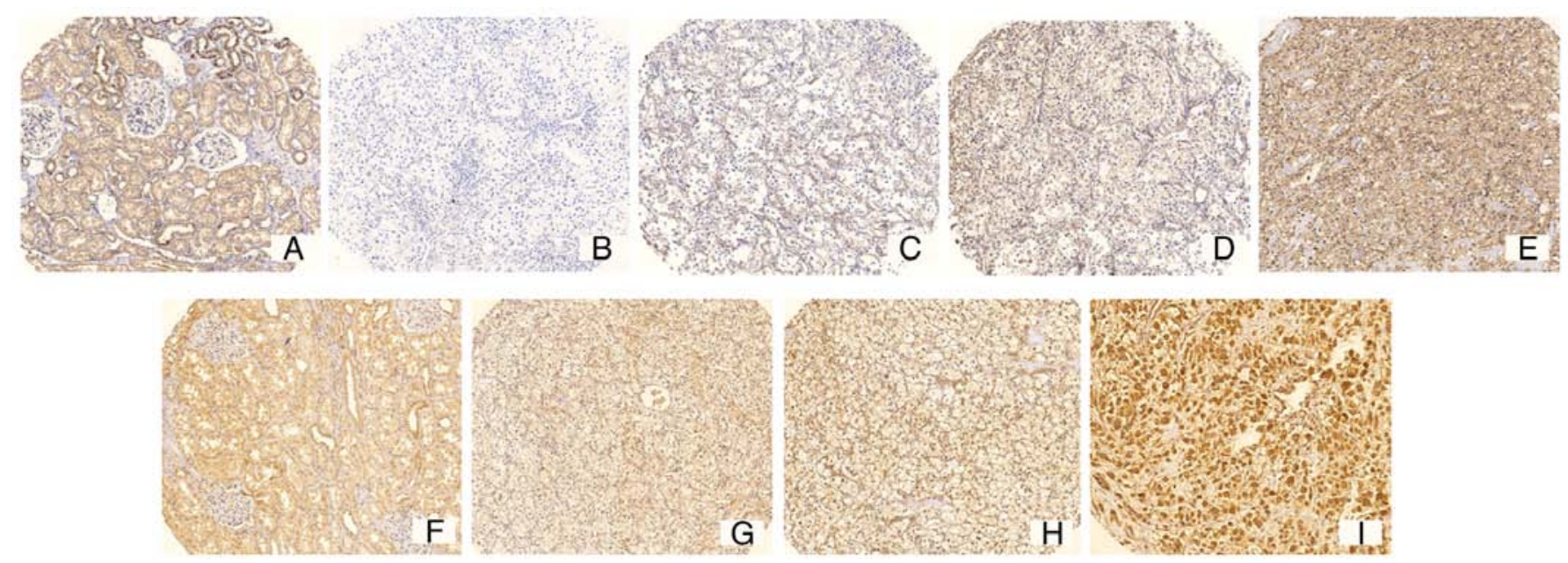

Figure 1. Representative images of the grading system used in the tissue microarray analysis. (A-E) Different staining intensities of PARK2 in (A) non-malignant and (B-E) ccRCC tissue are shown; (B) negative, (C) weakly positive, (D) moderately positive, (E) strongly positive. (F-I) Different staining intensities of CKS2 in (F) non-malignant (G-I) and ccRCC tissue (G) weakly positive, (H) moderately positive, (I) strongly positive.
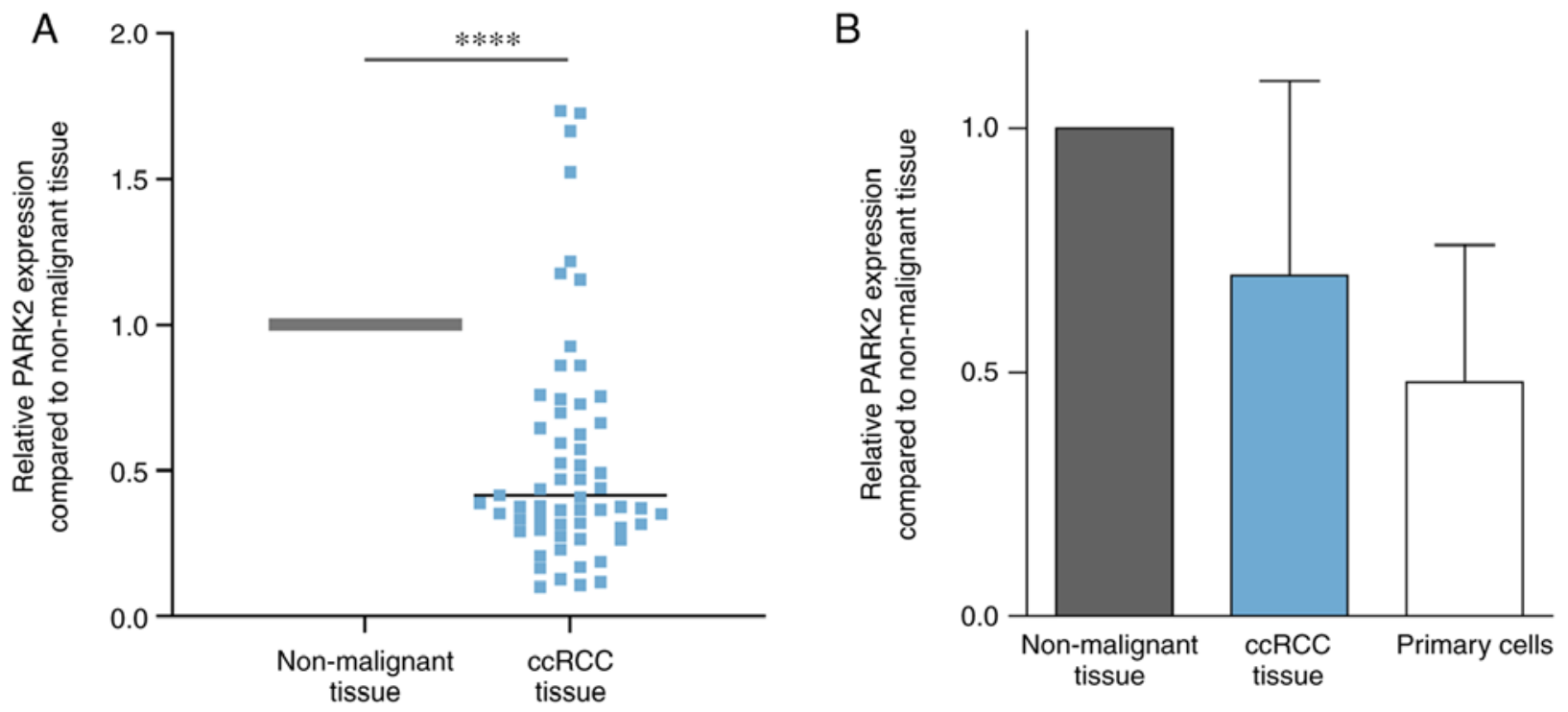

Figure 2. PARK2 mRNA is downregulated in ccRCC tissues and primary cells compared with non-malignant tissue. (A) PARK2 mRNA expression was examined by RT-qPCR, which showed lower PARK2 expression in tumor tissue of patients with ccRCC compared with non-malignant tissue. Data were analyzed using Wilcoxon signed-rank test; $\mathrm{n}=63$; ${ }^{* * * * *} \mathrm{P}<0.0001$. (B) PARK2 mRNA expression levels in ccRCC tissue and primary cells compared with non-malignant tissue was measured by RT-qPCR. ccRCC tissue showed decreased PARK2 mRNA expression levels compared with non-malignant tissue, which were reduced even more when cells were cultivated. Data are presented as the mean \pm SEM; $\mathrm{n}=7$. ccRCC, clear cell renal cell carcinoma; PARK2, parkin; RT-qPCR, reverse transcription-quantitative PCR.

\section{Results}

PARK2 mRNA expression levels are downregulated in tumor tissue and upon cultivation. PARK2 mRNA expression levels were analyzed in ccRCC tissue samples from 63 patient samples. The data revealed that PARK2 expression was significantly lower in ccRCC tissue compared with in adjacent non-malignant control tissue (Fig. 2A). As most commercially available cell lines do not express PARK2, samples from seven patients with ccRCC were cultivated to establish tumor primary cell lines (15). The clinicopathological data of the established primary cell lines are depicted in Table I. Following successful establishment, PARK2 mRNA expression levels were compared between the established primary cell cultures derived from ccRCC tumors, the fresh-frozen ccRCC tissue and the fresh-frozen corresponding non-malignant tissue (Fig. 2B). In most patients, PARK2 was downregulated in the tumor tissue as expected; however, PARK2 levels were decreased after primary cell establishment compared with in the original ccRCC tissue (Fig. 2B), which suggested a selective pressure in favor of cells lacking PARK2. The low levels of PARK2 in cultivated primary cells restrict them for thorough characterization of PARK2.

Overexpression of PARK2 elicits anti-migratory and anti-invasive effects on cells. Since neither any commercial ccRCC cell lines nor the established primary cells express PARK2, stable cells overexpressing PARK2 were established 
A

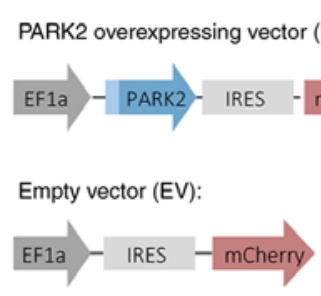

B

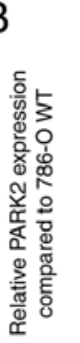

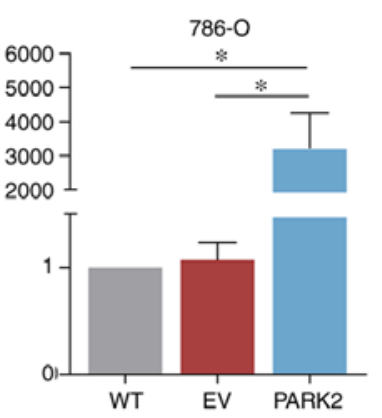

C
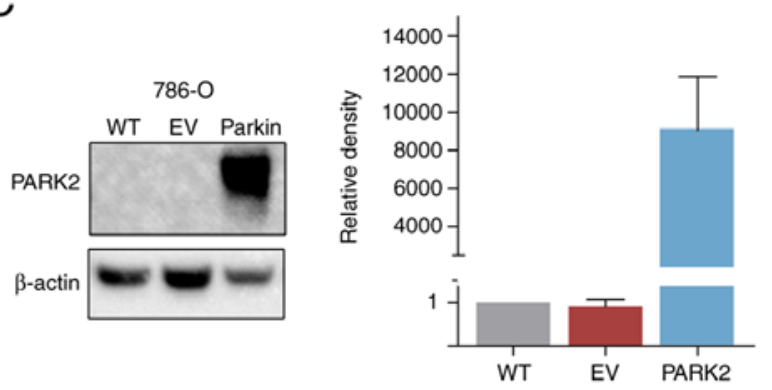

D
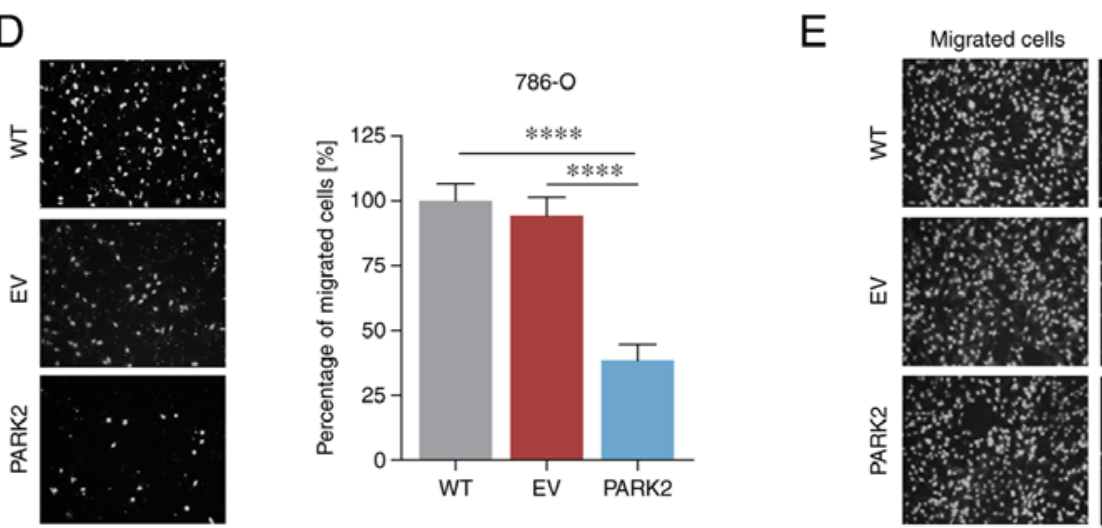

Invasive cells
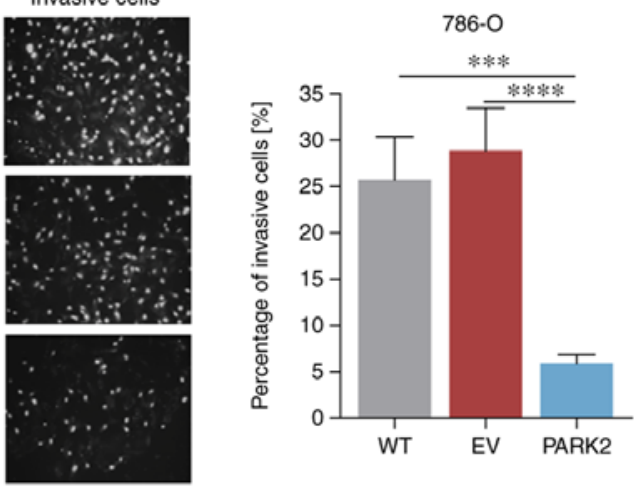

Figure 3. Generation and functional analyses of cell lines. (A) Transduction of ccRCC cell lines with a lentiviral vector with or without PARK2. (B) PARK2 mRNA expression was examined by reverse transcription-quantitative PCR, which showed higher mRNA expression levels in PARK2-transduced cells. TATA-box binding protein and $\beta$-actin were used as housekeeping genes. Kruskal-Wallis test was performed followed by Dunn's post hoc test; ${ }^{*}<0.05$. (C) PARK2 protein expression levels were assessed by immunoblotting of the different transduced cell lines. $\beta$-actin was used as a loading control. Adjusted densities were measured in GraphPad Prism version 8.2.0. (D) Transwell Boyden chamber migration assays were performed, which demonstrated a difference in migrative capacity after 6-8 $\mathrm{h}$ incubation. Magnification, $\mathrm{x} 10$. Data were compared by Kruskal-Wallis followed by Dun's; $\mathrm{n}=3$; ${ }^{* * * *} \mathrm{P}<0.0001$. (E) PARK2 overexpression reduced the invasiveness compared with control cells after $48 \mathrm{~h}$ incubation. Magnification, x10. Kruskal-Wallis test was performed followed by Dunn's post hoc test; $\mathrm{n}=3 ;{ }^{* * * *} \mathrm{P}<0.001,{ }^{* * * * *} \mathrm{P}<0.0001$. Data are presented as the mean $\pm \mathrm{SEM}$ of triplicate experiments. EF1a, elongation factor $1 \alpha$; EV, empty vector; IRES, internal ribosomal entry site; PARK2, parkin; RT-qPCR, reverse transcription-quantitative PCR; WT, wild-type.

by lentiviral transduction in $786-\mathrm{O}$ cells $\left(786-\mathrm{O}^{\mathrm{PARK} 2}\right)$, which were subsequently selected by flow cytometry. As a control, the empty vector (EV) was transduced into $786-\mathrm{O}$ cells $\left(786-\mathrm{O}^{\mathrm{EV}}\right.$; Fig. 3A) RT-qPCR of the generated cell lines validated the strong overexpression of PARK2 mRNA and western blotting showed a clear signal in the transduced cells (Fig. 3B and C, respectively).

To observe the effects of PARK2 expression on phenotypic features, several functional assays were conducted. PARK2 has been shown to serve a role in tumor progression and metastasis (10,33); therefore, the effects of PARK 2 overexpression on cell cycle progression, apoptosis, and migratory and invasive capacities were examined in vitro. While PARK2 overexpression had no effect on the cell cycle or apoptosis (Fig. S2A and B), differences in the migratory and invasive behavior were revealed between wild-type and PARK2-overexpressing cells. In contrast to 786-O and 786- $\mathrm{O}^{\mathrm{EV}}$ cells, 786-O $\mathrm{O}^{\text {PARK2 }}$ cells exhibited a significantly lower migratory capacity, which was reduced by $>50 \%$ (Fig. 3D). The overexpression of PARK 2 also significantly reduced the invasive behavior of cells (Fig. 3E). No significant differences in migratory or invasive ability were identified between WT 786-O and 786- $\mathrm{O}^{\mathrm{EV}}$ cells. To determine the reason for the phenotypic differences, 3 'mRNA sequencing was conducted. However, the only significant differentially expressed gene was PARK2 (Fig. S3; Table SII) indicating that PARK2 overexpression did not affect gene expression, leaving the explanation for the phenotypic observations unknown.
LC-MS shows lower CKS2 levels in the presence of PARK2. PARK2 functions as an E3 ubiquitin-protein ligase that specifically sequesters and marks proteins for degradation (14). Therefore, it was hypothesized that there may be a potential shift in the proteome upon overexpression of PARK2, and this was examined by LC-MS analysis. When comparing 786-O and the control $786-\mathrm{O}^{\mathrm{EV}}$, four proteins were identified with different expression levels ( $\log _{2} \mathrm{FCl}>1$; Fig. 4A; Table SIIIC). A total of 43 proteins exhibited a difference in abundance between 786-O ${ }^{\text {PARK2 }}$ and wild-type cells (Table SIIIA) and 38 differentially expressed proteins were identified between 786-O ${ }^{\text {PARK2 }}$ and 786-O ${ }^{\text {EV }}$ (Fig. 4A; Table SIIIB). Only two proteins, namely ubiquitin-conjugating enzyme E2 $\mathrm{Z}$ and oxysterol-binding protein-like 10 (OSBPL10), had an FDR score $<0.05$. Owing to the role of PARK2 as an E3 ubiquitin ligase, only those proteins that were upregulated in absence of PARK2 overexpression were selected; which was the case for 29 proteins in both conditions $\left(786-\mathrm{O}^{\mathrm{WT}}\right.$ and $\left.786-\mathrm{O}^{\mathrm{EV}}\right)$. Proteins were further selected by investigating if they are considered unfavorable prognostic markers in ccRCC and if they have been linked to a migrative phenotype in the literature (34-36). One protein that stood out and had a similar adjusted P-value as PARK2 was CKS2, which is one of the top 20 most upregulated proteins in $786-\mathrm{O}^{\mathrm{EV}}$ cells compared to 786-O ${ }^{\text {PARK2 }}$ (Table SIIIB). The profile plots illustrate the relative abundance of the identified PARK2 and CKS2 peptides for each replicate. A higher abundance of PARK2 is observed 
A

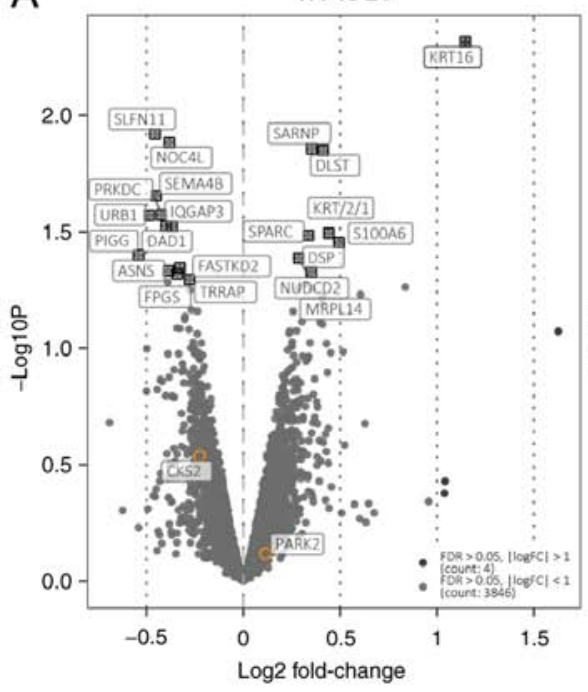

B Protein: 060260 (PARK2)

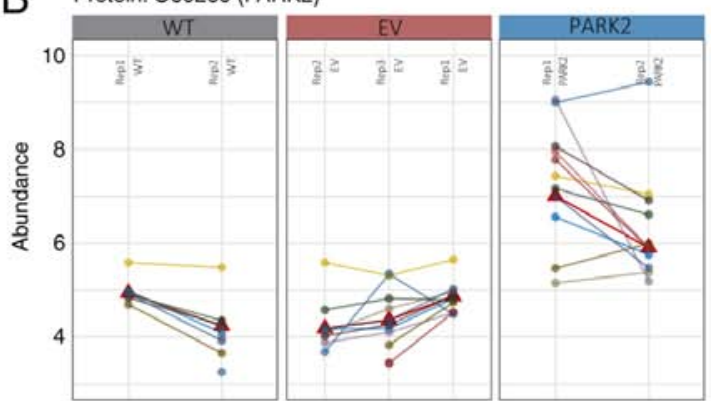

WT vs PARK2

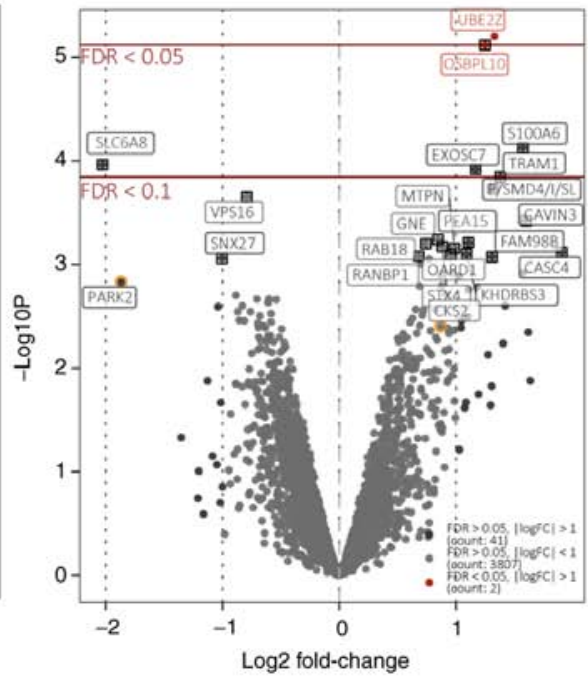

EV vs PARK2

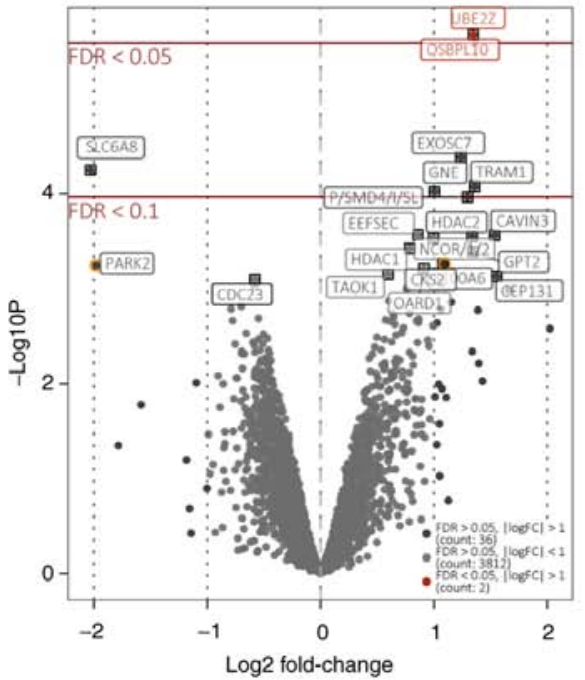

C Protein: P33552 (CKS2)

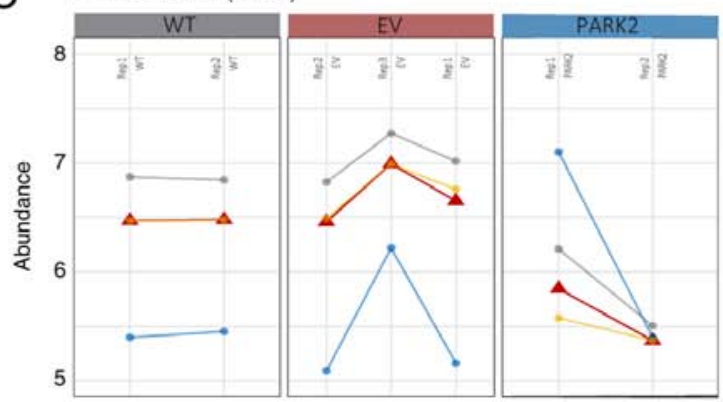

Figure 4. CKS2 protein levels are reduced in cells overexpressing PARK2. (A) Volcano plots depicting differential protein expression in the different transduced cells. Only slight differences in protein levels were observed for 786- $\mathrm{O}^{\mathrm{WT}}$ and $786-\mathrm{O}^{\mathrm{EV}}$ cells (llog $\mathrm{l}_{2} \mathrm{FCl}>1$; count, 4), bigger differences were observed when comparing 786-O [ $\log _{2} \mathrm{FCl}>1$; count, 43 (2 with FDR $\left.\left.<0.05\right)\right]$ or $786-\mathrm{O}^{\mathrm{EV}}$ cells $\left[\log _{2} \mathrm{FCl}>1\right.$; count, 38 (2 with FDR $\left.\left.<0.05\right)\right]$ with $786-\mathrm{O}^{\mathrm{PARK} 2}$ cells (B) Profile plots illustrated that the abundance of PARK2 peptides were increased in 786-O ${ }^{\text {PARK2 }}$ cells. (C) Abundance of CKS2 peptides was decreased in 786-O ${ }^{\text {PARK2 }}$ cells. CKS2, CDC28 protein kinase regulatory subunit 2; EV, empty vector; FC, fold change; PARK2, parkin; WT, wild-type.

in 786-O $\mathrm{O}^{\mathrm{PARK} 2}$, whereas a lower abundance of CKS2 peptides is detected in the same cell derivates (Fig. 4B and C).

Ubiquitin ligase function of PARK2 is needed for its effect on migration, which can be reduced by silencing CKS2 directly. PARK2 serves a role in several different cellular mechanisms $(9,12,35,36)$. To investigate if CKS2 levels are altered due to the activity of PARK2 as an E3 ubiquitin ligase, a mutation was introduced in the catalytic site of PARK2, which has been described to abolish this function (37). Cells were transduced with lentiviral vectors containing the PARK2 C431S mutation (786-O ${ }^{\mathrm{C} 431 \mathrm{~S}}$ and RCC-MH ${ }^{\mathrm{C} 431 \mathrm{~S}}$; Fig. 5A). PARK2 and CKS2 mRNA expression levels were evaluated by RT-qPCR and, as expected, PARK2 levels were higher in PARK2 overexpressed cells and cells harboring the C431S mutation (Fig. 5B). In addition, CKS2 mRNA expression levels were not altered by introduction of PARK2 overexpression, including PARK2 ${ }^{\mathrm{C} 431 \mathrm{~S}}$, which indicated, along with RNA sequencing results, that altered levels of PARK2 have no effect on the gene expression of CKS2 (Fig. 5C).

In addition, the effect of the C431S mutation on the migration of ccRCC cell lines was examined. Expression of the ligase-deficient PARK2 ${ }^{\mathrm{C} 431 \mathrm{~S}}$ did not elicit an effect on cell migration compared with PARK2-overexpressing cells; the migratory capacity was increased compared to that in PARK2-overexpressing cells and similar to that in the controls (Fig. 5D). This result suggested that the E3 ligase activity of PARK2 may be responsible for the decrease in cell migration. Since the MS analysis showed lower CKS2 protein levels upon upregulation of PARK2, and the effect seemed to be attributable to the E3 ligase activity, it was hypothesized that interference with CKS2 levels could elicit similar effects. Using siRNA, CKS2 expression was knocked down in wild-type and EV-transfected control cells (Fig. 5E), which resulted in a similar migration rate compared with cells overexpressing PARK2 (Fig. 5F and G). When CKS2 was silenced in cells overexpressing PARK2, cells exhibited a slight decrease in migration compared with cells overexpressing PARK2 that were transfected with scramble siRNA; however, no significant difference was identified. These data suggested that CKS2 is not completely regulated by PARK2, but instead receives other signaling cues that affect the migratory behavior of the cells.

High CKS2 levels are associated with lower survival and higher tumor grade in patients. As it was demonstrated that CKS2 levels affect the migratory and invasive behavior of ccRCC cell lines, the effects of CKS2 levels on patient survival were examined. TMAs of 262 patients with known 
A

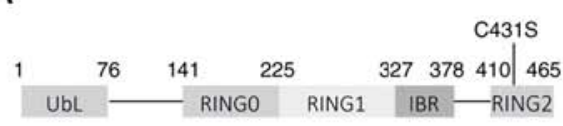

PARK2 C431S mutant vector (C431S):

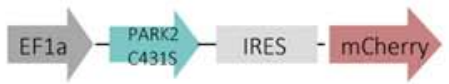

B
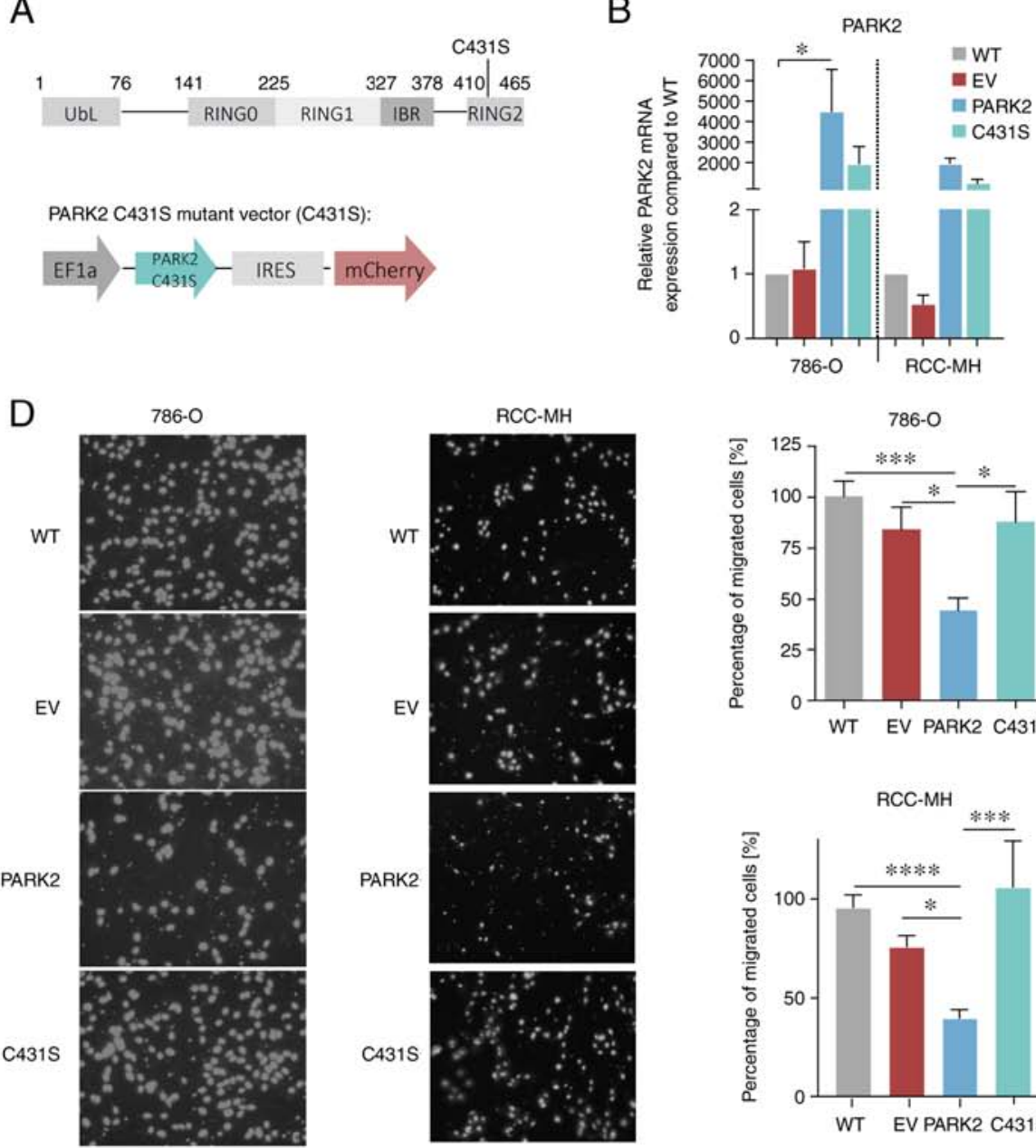
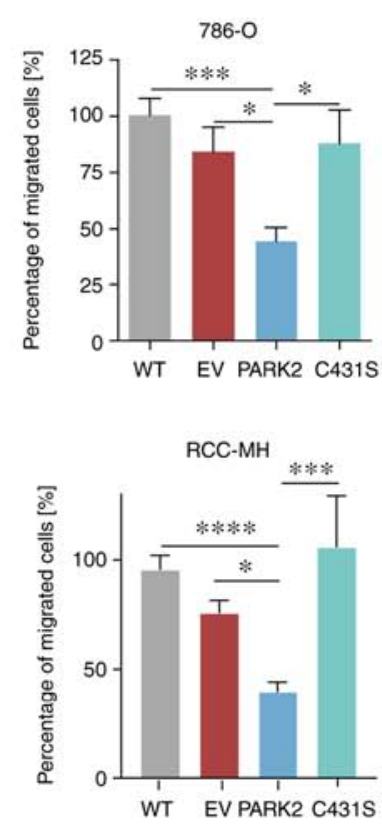

G

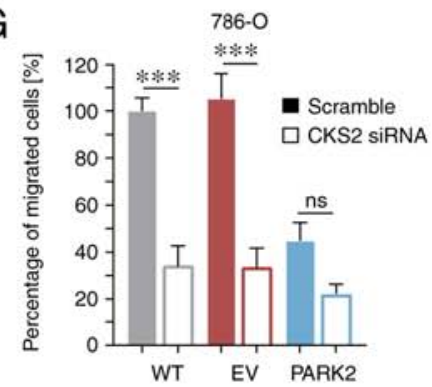

EV

E
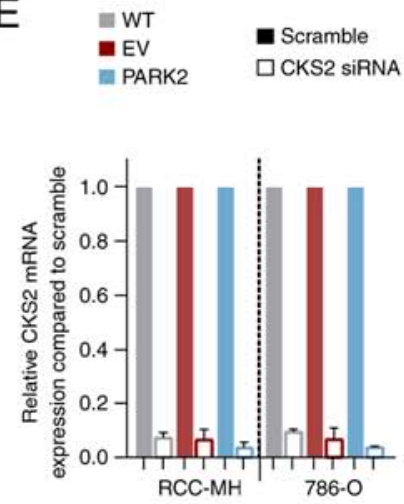

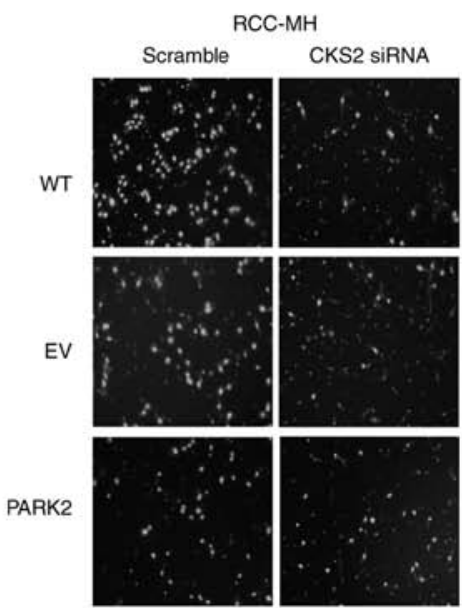

C
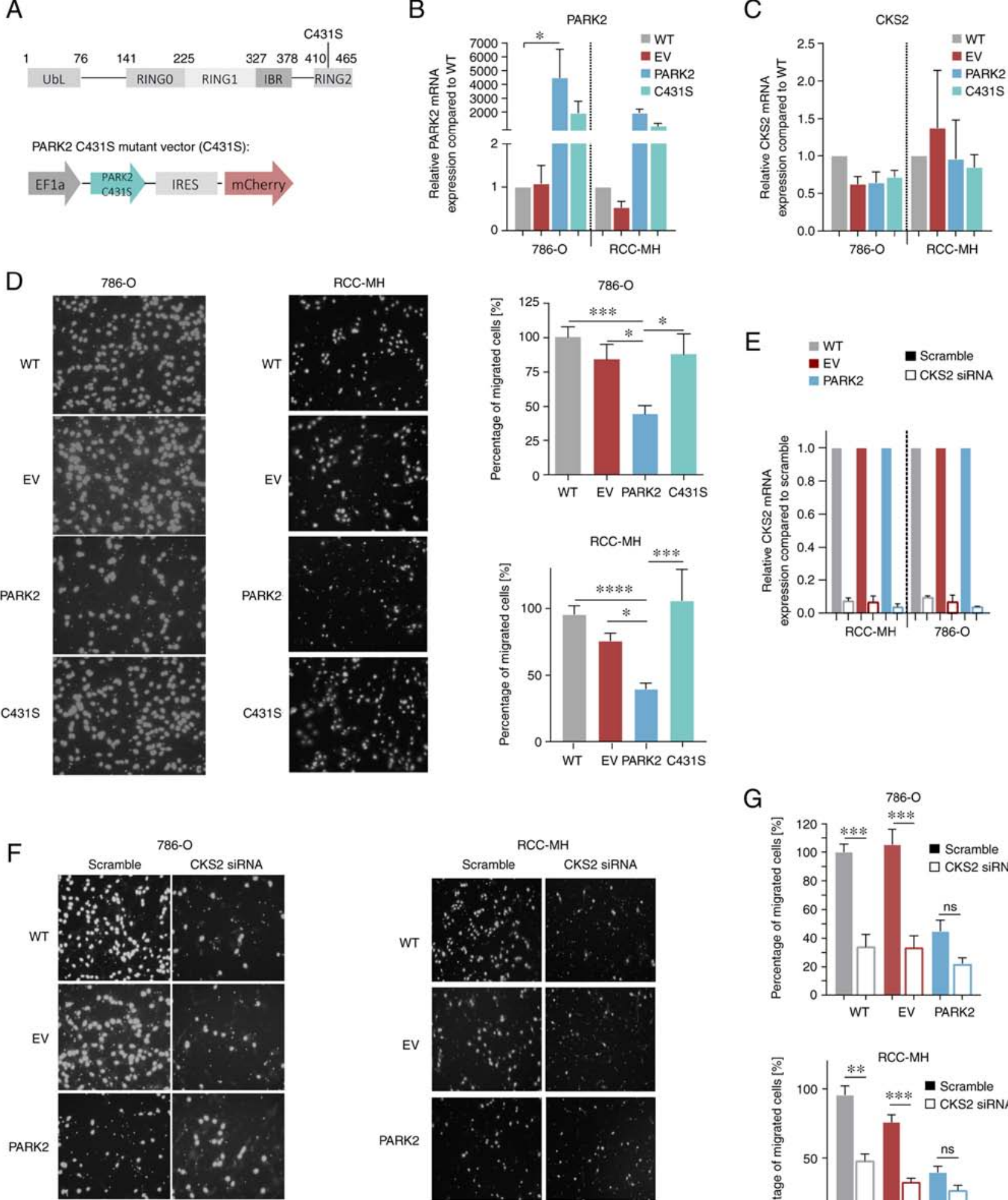

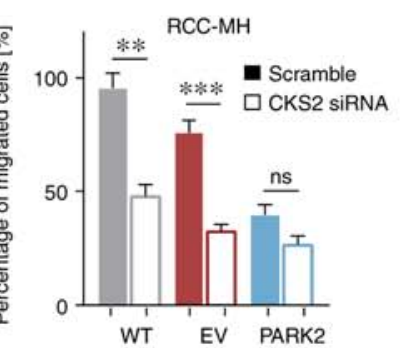

Figure 5. An inactive catalytic domain mutant 786- $\mathrm{O}^{\mathrm{C} 431 \mathrm{~S}}$ exhibits a similar phenotype as the control cells. (A) Cells with a PARK2 C431S mutation were generated by transducing cells with the pLVX-EF1a-PARKC431S-IRES-mCherry plasmid. (B) PARK2 mRNA expression levels were examined by RT-qPCR. TBP and $\beta$-actin were used as housekeeping genes. Data are presented as the mean + SEM of triplicate experiments. Kruskal-Wallis test was performed followed by Dunn's post hoc test; "P<0.05. (C) RT-qPCR analysis revealed no difference in CKS2 mRNA expression levels between the different transduced ccRCC cell lines. Data are presented as the mean \pm SEM. (D) Transwell Boyden chamber migration assays were conducted with mutant cell lines $786-\mathrm{O}^{\mathrm{C} 431 \mathrm{~S}}$ and RCC-MH ${ }^{\mathrm{C} 431 \mathrm{~s}}$. Magnification, x10. Data were compared by Kruskal-Wallis followed by Dunn's post hoc test; $\mathrm{n}=3 ;{ }^{*} \mathrm{P}<0.05,{ }^{* * * *} \mathrm{P}<0.001,{ }^{* * * * *} \mathrm{P}<0.0001$. (E) CKS2 mRNA expression levels were assessed after siRNA knockdown. The experiment was conducted in triplicate. TBP and $\beta$-actin served as housekeeping genes. Data are presented at the mean \pm SEM. (F) Migratory capacity was assessed after siRNA-mediated knockdown of CKS2 and (G) significance was assessed by Kruskal-Wallis followed by Dunn's post hoc test; $\mathrm{n}=2 ;{ }^{* *} \mathrm{P}<0.01,{ }^{* * *} \mathrm{P}<0.001$. Magnification, $\mathrm{x} 10$. ccRCC, clear cell renal cell carcinoma; CKS2, CDC28 protein kinase regulatory subunit 2; EF1a, elongation factor $1 \alpha$; EV, empty vector; IBR, in-between RING fingers domain; IRES, internal ribosome entry site; ns, not significant; PARK2, parkin; RT-qPCR, reverse transcription-quantitative PCR; siRNA, small interfering RNA; TBP, TATA-box binding protein; Ubl, ubiquitin-like domain; WT, wild-type. 
A

CKS2

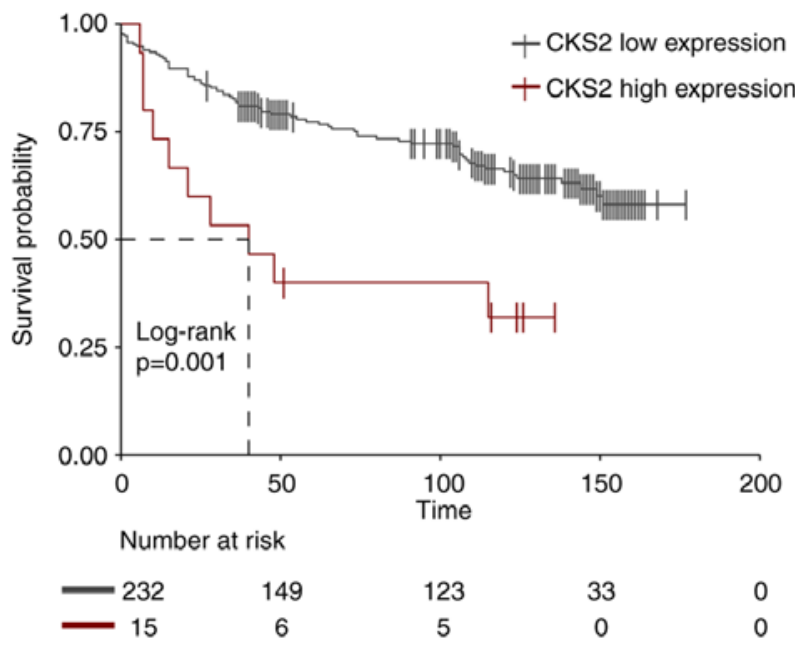

C

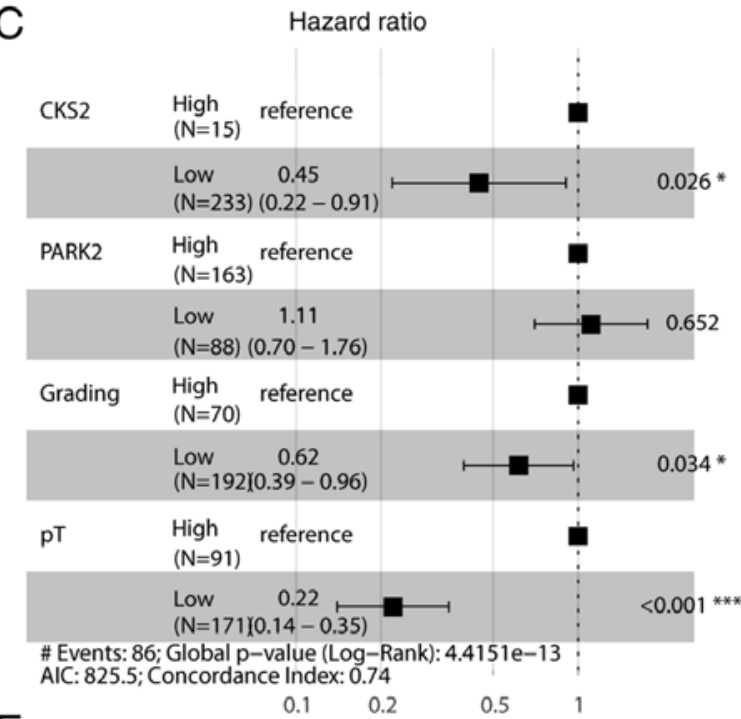

E

\begin{tabular}{|c|l|l|}
\hline \multicolumn{2}{|c|}{ CKS2 } \\
\hline \multirow{2}{*}{ Grading } & Spearman's rho & 0.1586622 \\
\cline { 2 - 3 } & p-value & $\mathbf{0 . 0 1 2 3 5}$ \\
\hline \multicolumn{2}{|c|}{ PARK2 } \\
\hline \multirow{2}{*}{ Grading } & Spearman's rho & -0.06371953 \\
\cline { 2 - 3 } & $p$-value & 0.3147 \\
\hline
\end{tabular}

B

PARK2

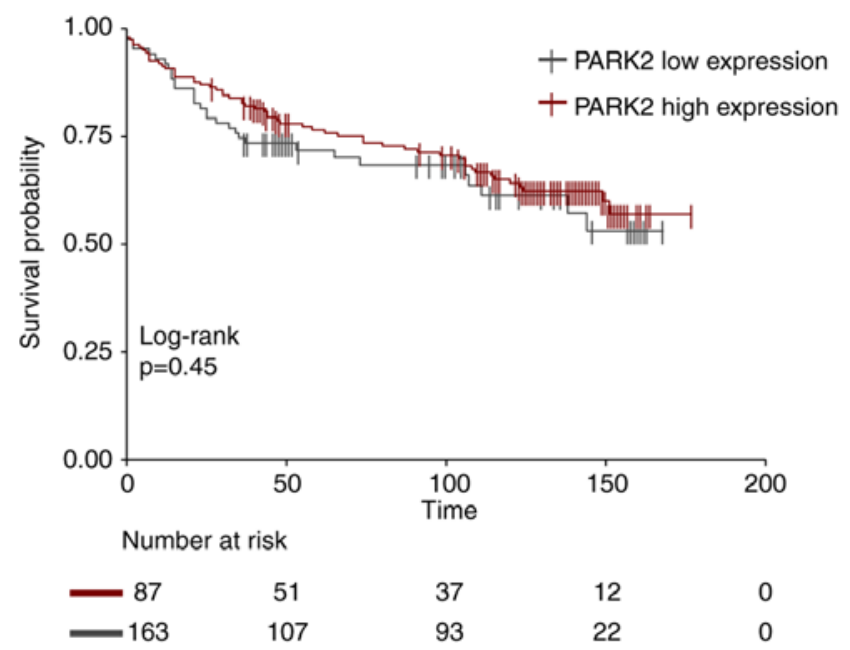

D

\begin{tabular}{|l|l|l|}
\hline \multicolumn{3}{|c|}{ CKS2 } \\
\hline \multirow{4}{*}{ pT } & Pearson's r & 0.07748843 \\
\cline { 2 - 4 } & p-value & 0.224 \\
\cline { 2 - 4 } & $95 \% \mathrm{Cl}$ & $-0.04753756,0.20012387$ \\
\cline { 2 - 4 } & t-stat & 1.219 \\
\hline & df & 246 \\
\hline \multirow{4}{*}{ pT } & Pearson's r & -0.1259917 \\
\cline { 2 - 4 } & p-value & $\mathbf{0 . 0 4 6 1 4}$ \\
\cline { 2 - 4 } & $95 \%$ Cl & $-0.245973676,-0.002206968$ \\
\hline & t-stat & -2.0041 \\
\cline { 2 - 4 } & df & 249 \\
\hline
\end{tabular}

$\mathrm{F}$

\begin{tabular}{|l|l|l|}
\hline \multicolumn{2}{|c|}{ PARK2 } \\
\hline \multirow{4}{*}{ CKS2 } & Pearson's r & 0.06341729 \\
\cline { 2 - 3 } & p-value & 0.3093 \\
\cline { 2 - 3 } & $95 \% \mathrm{Cl}$ & -0.05892689 \\
\cline { 2 - 3 } & t-stat & 1.0187 \\
\cline { 2 - 3 } & df & 257 \\
\hline
\end{tabular}

Figure 6. Elevated CKS2 levels are associated with poor survival in patients with ccRCC. (A) Kaplan-Meier curves of the survival probability showing an improved overall survival for patients with low CKS2 expression levels compared with high CKS2 levels. Significance was assessed with log-rank test. Number at risk indicates the number of patients which are still alive at given time point; $n=247$. (B) Kaplan-Meier curves followed by log-rank test showing no significant difference in overall survival for patients with high PARK2 expression levels compared with low PARK2 levels; $n=250$. (C) Cox proportional hazard ratio showing an association between survival and different parameters, such as CKS2 expression, PARK2 expression, tumor grade and pT. "P $<0.05$, ${ }^{* * * *} \mathrm{P}<0.001$ (D) Pearson's correlation analysis depicts a relationship between PARK2 and pT. In addition, CKS2 and pT were also analyzed. Bold values indicate significant p-values. (E) Spearman's correlation of CKS2 and grading as well as PARK2 and grading are depicted. (F) Pearson's correlation between CKS2 and PARK2 including Pearson's r, P-value, 95\% CI, t-stat and df. ccRCC, clear cell renal cell carcinoma; CI, confidence interval; CKS2, CDC28 protein kinase regulatory subunit 2; df, degrees of freedom; PARK2, parkin; pT, pathologic tumor stage; $t$-stat, $t$-statistic.

clinicopathological data (Table II) were prepared to analyze the survival probability and correlation between different parameters. Kaplan-Meier survival curves indicated a significantly lower survival for patients with high CKS2 expression. The median survival for patients with high CKS2 expression was 40 months, whereas patients with low CKS2 expression did not reach median survival even after 150 months (Fig. 6A).
Furthermore, patients with high levels of PARK2 showed a trend towards better survival; however, the data were not significantly different (Fig. 6B). Cox proportional hazards regression analysis revealed a significantly improved survival for patients with low CKS2 protein levels, low grading (G1 or G2), and low tumor staging (pT; T1 or T2). Patients with high PARK2 protein levels had a tendency towards better survival, 
although not significantly different (Fig. 6C). Grading and CKS2 and PARK2 levels were analyzed using Spearman's correlation analysis. CKS2 and grading showed a weak positive correlation with $\mathrm{Q}=0.159$ and $\mathrm{P}=0.012$ (Fig. 6E). PARK2 and grading were not significantly correlated $(r=-0.064$ and $\mathrm{P}=0.315$; Fig. $6 \mathrm{E})$. The statistical relationship between different parameters (CKS2, PARK2 and pT) were examined by Pearson's correlation analysis. CKS2 and pT showed a tendency towards a positive correlation $(\mathrm{r}=0.077)$; however, no significance was identified $(\mathrm{P}=0.224)$. Analysis of PARK2 and pT showed a weak negative correlation $(r=-0.126$ and $P=0.046$; Fig. 6D). Grading and CKS2 and PARK2 levels were analyzed using Spearman's correlation analysis. CKS2 and grading showed a weak positive correlation $(\varrho=0.159$ and $\mathrm{P}=0.012$; Fig. 6E). PARK2 and grading were not significantly correlated $(\mathrm{r}=-0.064$ and $\mathrm{P}=0.315$; Fig. 6E). Analysis between PARK2 and CKS2 showed no correlation $(r=0.063$ and $\mathrm{P}=0.309$; Fig. 6F).

\section{Discussion}

The present study demonstrated that PARK2 overexpression elicited anti-migratory and anti-invasive behavior in ccRCC cells. Furthermore, PARK2 appeared to influence CKS2 protein expression levels through its protein degrading function, since higher protein levels were found in cells without PARK2. The increased migratory behavior due to PARK2 deficiency was rescued by silencing CKS2. Moreover, high levels of CKS2 were positively associated with lower patient survival and weakly correlated with higher tumor grading. All together, these results indicated CKS2 as a potential, interesting biomarker candidate and a possible suitable therapeutic target.

PARK2 is downregulated in numerous types of cancer $(5,6)$. Downregulation or absence of PARK2 owing to mutation, loss of heterozygosity or promoter hypermethylation is associated with worse prognosis in several cancer types (38). Previous studies have investigated the diverse functions of PARK2 in different types of cancer; however, extensive knowledge about the biological function of PARK2 in ccRCC is still lacking. Therefore, the present study aimed to thoroughly investigate the effects of PARK2 expression differences on ccRCC cells. It was demonstrated that cells overexpressing PARK2 had a lower migratory and invasive capacity in vitro. This tumor suppressive phenotype linked to PARK2 expression has been observed previously in different cancer types, including non-small cell lung cancer (39), breast cancer (10) and nasopharyngeal carcinoma (31). Notably, PARK2 deficiency in melanoma cells suppressed migration by inhibiting mitofusin 2 (MFN2) ubiquitination; however, contradictorily, malignant melanoma and metastatic malignant melanoma tissue analyses revealed higher levels of PARK2 and MFN2 (40). This discrepancy highlights the contradiction within the biology of PARK2 and the several roles within the cell and, therefore, its different effects on tumor pathogenesis. Hence, the precise function of PARK2 under certain conditions needs to be further investigated to find the exact target proteins that are ubiquitinated by PARK2. Moreover, owing to its role as a tumor suppressor in ccRCC, PARK2 is not a suitable candidate for therapeutic approaches. However, proteins that are increased in cells without PARK2 expression and promote tumorigenesis might serve as an interesting option in treating patients.

Owing to the observed migratory phenotype and the role of PARK2 as an E3 ubiquitin protein ligase, it was hypothesized that it is the accumulation of proteins that promote malignancy, such as migration and invasion. LC-MS results showed higher proteins levels in absence of PARK2. To refine the list of putative interesting proteins, only those that have been considered as unfavorable prognostic markers in ccRCC were investigated. One such protein, OSBPL10, is considered a favorable prognostic marker in ccRCC; however, this disagreed with the phenotypic findings of the present study, making it unattractive for further investigations (41). Notably, PARK2 did not show any significance in the LC-MS analysis in 786- $\mathrm{O}^{\text {PARK2 }}$ cells, yet, the high levels of mRNA and protein expression in cells transduced with a vector overexpressing PARK2 were verified. Thus, the protein PARK2 serves as an internal control in 786- $\mathrm{O}^{\text {PARK2 }}$ cells. Therefore, we assumed that we can be confident about proteins showing a similar level of significance in the LC-MS analysis as PARK2. Moreover, following a review of the literature on proteins that have been described with the phenotype observed in the present study, one protein which stood out and has been reported to be associated with malignancy was CKS2 $(33,34)$. CKS2 was increased in cells with low PARK2 levels suggesting that PARK2 might regulate CKS2 levels, which, in turn, may cause a less aggressive phenotype. CKS2 is highly expressed in numerous tumor types and is associated with metastasis (32-34). It binds to the catalytic subunit of cyclin-dependent kinases and is responsible for cell cycle progression (42). Besides its involvement in the cell cycle, CKS2 has been described to serve a role in mitochondrial function in cervical cancer. CKS2 forms a complex with single-stranded DNA-binding protein 1 and influences mitochondrial DNA replication, which controls the energy supply of the cell and, subsequently, the aggressiveness of the tumor cells (43). Moreover, PARK2 monitors mitochondrial quality control by selectively degrading defective mitochondria (44). The opposing expression levels of PARK2 and CKS2, as well as their roles in mitochondrial function and tumor aggressiveness suggested a possible link between those proteins.

Previous studies have shown that silencing CKS2 increased caspase-3 activity and Bax expression in gastric cancer and cholangiocarcinoma cells, indicating that CKS2 depletion promotes apoptosis $(45,46)$. Furthermore, it was reported that CKS2 interference may result in $\mathrm{G}_{2}$ cell cycle arrest, which shows that increased CKS2 levels promote cholangiocarcinoma progression (46). Although several previous studies have investigated the effect on CKS2 depletion on migration in different cancer cells (47-49), no previous studies in ccRCC cells have been conducted. By inhibiting CKS2 in ccRCC wild-type and control cells, the migratory phenotype was reversed, which resulted in less aggressive behavior. Results from the present study, in addition to those from previously conducted studies, suggested a potential role for CKS2 as a therapeutic target in different cancer types. Moreover, CKS2 expression was significantly associated with lower survival and increased tumor grade. These findings indicated CKS2 not only as a potential therapeutic target, but also as a possible biomarker in ccRCC. 
To investigate the interaction between PARK2 and CKS2, a mutation (C431) was introduced into the catalytic site of the RING2 domain in PARK2, which led to the abolishment of PARK2 E3 ligase activity $(35,50)$. Cells harboring the C431S mutation displayed similar migratory capacities as wild-type cells. This observation indicated that the E3 ubiquitin-protein ligase activity of PARK 2 regulates proteins that influence the potential of a cell to migrate and invade, at least in in vitro experiments. Furthermore, it suggested that loss of PARK2 and the accompanied loss of the E3 function may have a strong effect on malignancy. In addition, the weak negative correlation between PARK2 expression and pT stage indicated a tumor suppressive capacity for PARK2. Moreover, the finding of CKS 2 as a potential target of PARK2 renders novel possibilities and a better understanding of ccRCC tumorigenesis.

In conclusion, ccRCC cells overexpressing PARK2 were revealed to be less aggressive compared with their counterparts, as shown by decreased migration and invasion in vitro. It was demonstrated that cells overexpressing PARK2 exhibited a downregulation of $\mathrm{CKS} 2$ protein expression levels. Using cells that do not overexpress PARK2, it was demonstrated that CKS2 silencing led to reduced migration and invasion. This indicated that the anti-migratory and anti-invasive effect of PARK2 is most likely mediated by CKS2 and that it is possible to reverse the phenotype in PARK2-deficient cells. It was further shown that the PARK $2^{\mathrm{C} 431 \mathrm{~S}} \mathrm{E} 3$ ligase mutant was more migrative, which suggested that the E3 ligase activity of PARK2 may be required to exert the anti-migrative and anti-invasive effect potentially by targeting CKS2. Patient data revealed that increased CKS2 expression was weakly positively correlated with tumor grading (thus, more aggressive tumor growth) and was associated with patient survival. Taken together, these results demonstrated that CKS2 may be a putative target of PARK2 and may serve as a potential candidate for new cancer therapy approaches.

\section{Acknowledgements}

We kindly thank Ms. Kerstin Fuchs (Institute of Pathology, University Hospital Bonn, Germany) for her excellent technical help. Moreover, we are grateful to Ms. Susanne Steiner (Institute of Pathology, University Hospital Bonn, Germany) and Ms. Seher Aktekin (Insitute of Pathology, University Hospital Bonn, Germany) for tissue microarray construction and staining, as well as to the BioBank of the University Hospital Bonn (Bonn, Germany) for providing the tissue for analysis. Furthermore, we thank the Medical Faculty University Bonn Core Facilities for next generation sequencing. Mass Spectrometry and Bioinformatics Data Analysis for their support. Acquisition of mass spectrometric data was performed at the Core Facility Mass Spectrometry, Institute of Biochemistry and Molecular Biology, Medical Faculty, University of Bonn.

\section{Funding}

No external funding was obtained for this study. The mass spectrometer was funded by the Deutsche Forschungsgemeinschaft (DFG, German Research Foundation; project no. 386936527).

\section{Availability of data and materials}

The data set for RNA sequencing presented in this study can be found in the online repository Sequence Read Archive (SRA) under the following accession no. PRJNA748615 (https://www. ncbi.nlm.nih.gov/sra). The data for MS have been deposited to the ProteomeXchange Consortium via the PRIDE (51) partner repository with the dataset identifier PXD029398 and 10.6019/PXD029398. All data are available from the corresponding author on reasonable request.

\section{Authors' contributions}

LKE, HS, GK and MIT conceived the project. LKE, VB and AGS designed the methodology. FS, AB and LKE performed the formal analysis. FS, LKE, GK, HS and CS curated the data. LKE prepared the original draft of the manuscript. LKE, HS and AGS reviewed and edited the manuscript. LKE prepared the figures. MIT and HS supervised the project. MIT led project administration. MIT and LKE confirm the authenticity of all the raw data. All authors have read and approved the final version of the manuscript.

\section{Ethics approval and consent to participate}

This study was performed on cell lines and on retrospectively biobank-archived or formaldehyde-fixed paraffin embedded material. All these studies were approved by the Ethics Committees (EK 233/20 and EK 219/17 University Hospital Bonn; and EA1/134/12 Charité University Medicine Berlin).

\section{Patient consent for publication}

Patient consent for publication is covered by biobank informed consent.

\section{Competing interest}

The authors declare that they have no competing interest.

\section{References}

1. Ferlay J, Ervik M, Lam F, Colombet M, Mery L, Piñeros M, Znaor A, Soerjomataram I and Bray F: Global cancer observatory: Cancer today. IARC, Lyon, 2020.

2. SEER*Explorer: An interactive website for SEER cancer statistics (Internet). Surveillance Research Program, National Cancer Institute, Bethesda, MD, 2021. https://seer.cancer.gov/explorer/. Accessed September 27, 2021.

3. American Society of Clinical Oncology (ASCO): Kidney cancer. ASCO, Alexandria, VA, 2021.

4. Padala SA, Barsouk A, Thandra KC, Saginala K, Mohammed A, Vakiti A, Rawla P and Barsouk A: Epidemiology of renal cell carcinoma. World J Oncol 11: 79-87, 2020.

5. Toma MI, Wuttig D, Kaiser S, Herr A, Weber T, Zastrow S, Koch R, Meinhardt M, Baretton GB, Wirth MP and Fuessel S: PARK2 and PACRG are commonly downregulated in clear-cell renal cell carcinoma and are associated with aggressive disease and poor clinical outcome. Genes Chromosomes Cancer 52: 265-273, 2013.

6. Poulogiannis G, McIntyre RE, Dimitriadi M, Apps JR, Wilson CH, Ichimura K, Luo F, Cantley LC, Wyllie AH, Adams DJ and Arends MJ: PARK2 deletions occur frequently in sporadic colorectal cancer and accelerate adenoma development in Apc mutant mice. Proc Natl Acad Sci USA 107: 15145-15150, 2010. 
7. Kitada T, Asakawa S, Hattori N, Matsumine H, Yamamura Y, Minoshima S, Yokochi M, Mizuno Y and Shimizu N: Mutations in the parkin gene cause autosomal recessive juvenile parkinsonism. Nature 392: 605-608, 1998.

8. Ikeuchi K, Marusawa H, Fujiwara M, Matsumoto Y, Endo Y, Watanabe T, Iwai A, Sakai Y, Takahashi R and Chiba T: Attenuation of proteolysis-mediated cyclin E regulation by alternatively spliced parkin in human colorectal cancers. Int J Cancer 125: 2029-2035, 2009.

9. Wang H, Liu B, Zhang C, Peng G, Liu M, Li D, Gu F, Chen Q, Dong JT, Fu L and Zhou J: Parkin regulates paclitaxel sensitivity in breast cancer via a microtubule-dependent mechanism. J Pathol 218: 76-85, 2009.

10. Liu J, Zhang C, Zhao Y, Yue X, Wu H, Huang S, Chen J, Tomsky K, Xie H, Khella CA, et al: Parkin targets HIF-1 $\alpha$ for ubiquitination and degradation to inhibit breast tumor progression. Nat Commun 8: 1823, 2017.

11. Liu K, Li F, Han H, Chen Y, Mao Z, Luo J, Zhao Y, Zheng B, $\mathrm{Gu} \mathrm{W}$ and Zhao W: Parkin regulates the activity of Pyruvate Kinase M2. J Biol Chem 291: 10307-10317, 2016.

12. Bernardini JP, Lazarou M and Dewson G: Parkin and mitophagy in cancer. Oncogene 36: 1315-1327, 2017.

13. Liu J, Zhang $\mathrm{C}, \mathrm{Hu} \mathrm{W}$ and Feng Z: Parkinson's disease-associated protein Parkin: An unusual player in cancer. Cancer Communications 38: 40, 2018

14. Shimura H, Hattori N, Kubo Si, Mizuno Y, Asakawa S, Minoshima S, Shimizu N, Iwai K, Chiba T, Tanaka K and Suzuki T: Familial Parkinson disease gene product, parkin, is a ubiquitin-protein ligase. Nat Genet 25: 302-305, 2000

15. Simon AG, Esser LK, Ellinger J, Branchi V, Tolkach Y, Müller S, Ritter M, Kristiansen G, Muders MH, Mayr T and Toma MI: Targeting glycolysis with 2-deoxy-D-glucose sensitizes primary cell cultures of renal cell carcinoma to tyrosine kinase inhibitors. J Cancer Res Clin Oncol 146: 2255-2265, 2020.

16. Livak KJ and Schmittgen TD: Analysis of relative gene expression data using real-time quantitative PCR and the 2(-Delta Delta C(T)) method. Methods 25: 402-408, 2001.

17. Kim D, Paggi JM, Park C, Bennett C and Salzberg SL: Graph-based genome alignment and genotyping with HISAT2 and HISAT-genotype. Nat Biotechnol 37: 907-915, 2019.

18. Li H, Handsaker B, Wysoker A, Fennell T, Ruan J, Homer N, Marth G, Abecasis G and Durbin R; 1000 Genome Project Data Processing Subgroup: The sequence alignment/map format and SAMtools. Bioinformatics 25: 2078-2079, 2009.

19. Liao Y, Smyth GK and Shi W: featureCounts: An efficient general purpose program for assigning sequence reads to genomic features. Bioinformatics 30: 923-930, 2014.

20. R Core Team: R: A language and environment for statistical computing. R Foundation for Statistical Computing, Vienna, 2021. https://www.R-project.org/.

21. Love MI, Huber W and Anders S: Moderated estimation of fold change and dispersion for RNA-seq data with DESeq2. Genome Biology, 15, 550, 2014.

22. Zhu A, Ibrahim JG and Love MI: Heavy-tailed prior distributions for sequence count data: Removing the noise and preserving large differences. Bioinformatics 35: 2084-2092, 2019.

23. Wickham H: ggplot2: Elegant graphics for data analysis 2nd edition. Springer, Cham, 2016.

24. León IR, Schwämmle V, Jensen $\mathrm{ON}$ and Sprenger RR: Quantitative assessment of in-solution digestion efficiency identifies optimal protocols for unbiased protein analysis. Mol Cell Proteomics 12: 2992-3005, 2013.

25. Masuda T, Tomita M and Ishihama $Y$ : Phase transfer surfactant-aided trypsin digestion for membrane proteome analysis J Proteome Res 7: 731-740, 2008.

26. Manza LL, Stamer SL, Ham A-JL, Codreanu SG and Liebler DC: Sample preparation and digestion for proteomic analyses using spin filters. Proteomics 5: 1742-1745, 2005

27. Wiśniewski JR, Zougman A, Nagaraj N and Mann M: Universal sample preparation method for proteome analysis. Nat Methods 6 : 359-362, 2009

28. Huber W, von Heydebreck A, Sueltmann H, Poustka A and Vingron M: Variance stabilization applied to microarray data calibration and to the quantification of differential expression. Bioinformatics 18 (Suppl 1): S96-S104, 2002.

29. Ritchie ME, Phipson B, Wu D, Law CW, Shi W and Smyth GK: limma powers differential expression analyses for RNA-sequencing and microarray studies. Nucleic Acids Res 43: e47, 2015.

30. Kassambara A, Kosinski M, Biecek P and Fabian S: Drawing Survival Curves using 'ggplot2'. https://cran.r-project.org/web/ packages/survminer/index.html. Accessed March 9, 2021
31. Ni H, Zhou Z, Jiang B, Yuan X, Cao X, Huang G and Li Y: Inactivation of parkin by promoter methylation correlated with lymph node metastasis and genomic instability in nasopharyngeal carcinoma. Tumour Biol 39: 101042831769502, 2017.

32. Huang $\mathrm{N}$, Wu $\mathrm{Z}$, Hong $\mathrm{H}$, Wang $\mathrm{X}$, Yang $\mathrm{F}$ and $\mathrm{Li} \mathrm{H}$ Overexpression of CKS2 is associated with a poor prognosis and promotes cell proliferation and invasion in breast cancer. Mol Med Rep 19: 4761-4769, 2019.

33. $\mathrm{Xu} \mathrm{JH}$, Wang Y and Xu D: CKS2 promotes tumor progression and metastasis and is an independent predictor of poor prognosis in epithelial ovarian cancer. Eur Rev Med Pharmacol Sci 23 3225-3234, 2019

34. Yu MH, Luo Y, Qin SL, Wang ZS, Mu YF and Zhong M Up-regulated CKS2 promotes tumor progression and predicts a poor prognosis in human colorectal cancer. Am J Cancer Res 5: 2708-2718, 2015

35. Riley BE, Lougheed JC, Callaway K, Velasquez M, Brecht E, Nguyen L, Shaler T, Walker D, Yang Y, Regnstrom K, et al: Structure and function of parkin E3 ubiquitin ligase reveals aspects of RING and HECT ligases. Nat Commun 4: 1982, 2013.

36. Singh K, Han K, Tilve S, Wu K, Geller HM and Sack MN: Parkin targets NOD2 to regulate astrocyte endoplasmic reticulum stress and inflammation. Glia 66: 2427-2437, 2018.

37. Wenzel DM, Lissounov A, Brzovic PS and Klevit RE: UBCH7 reactivity profile reveals parkin and HHARI to be RING/HECT hybrids. Nature 474: 105-108, 2011

38. Xu L, Lin D, Yin D and Koeffler HP: An emerging role of PARK2 in cancer. J Mol Med 92: 31-42, 2014.

39. Duan H, Lei Z, Xu F, Pan T, Lu D, Ding P, Zhu C, Pan C and Zhang S: PARK2 suppresses proliferation and tumorigenicity in non-small cell lung cancer. Front Oncol 9: 790, 2019.

40. Lee YS, Jung YY, Park MH, Yeo IJ, Im HS, Nam KT, Kim HD, Kang SK, Song JK, Kim YR, et al: Deficiency of parkin suppresses melanoma tumor development and metastasis through inhibition of MFN2 ubiquitination. Cancer Lett 433: 156-164, 2018.

41. Uhlen M, Zhang C, Lee S, Sjöstedt E, Fagerberg L, Bidkhori G, Benfeitas R, Arif M, Liu Z, Edfors F, et al: A pathology atlas of the human cancer transcriptome. Science 357: eaan2507, 2017.

42. Kakarougkas A, Ismail A, Chambers AL, Riballo E, Herbert AD Künzel J, Löbrich M, Jeggo PA and Downs JA: Requirement for PBAF in transcriptional repression and repair at DNA breaks in actively transcribed regions of chromatin. Mol Cell 55: 723-732, 2014.

43. Jonsson M, Fjeldbo CS, Holm R, Stokke T, Kristensen GB and Lyng H: Mitochondrial function of CKS2 oncoprotein links oxidative phosphorylation with cell division in chemoradioresistant cervical cancer. Neoplasia 21: 353-362, 2019.

44. Durcan TM and Fon EA: The three 'P's of mitophagy: PARKIN, PINK1, and post-translational modifications. Genes Dev 29: 989-999, 2015.

45. Tanaka F, Matsuzaki S, Mimori K, Kita Y, Inoue H and Mori M: Clinicopathological and biological significance of CDC28 protein kinase regulatory subunit 2 overexpression in human gastric cancer. Int J Oncol 39: 361-372, 2011.

46. Shen DY, Zhan YH, Wang QM, Rui G and Zhang ZM: Oncogenic potential of cyclin kinase subunit-2 in cholangiocarcinoma. Liver Int 33: 137-148, 2013.

47. Hua K, Jin J, Zhang $\mathrm{H}$, Zhao B, Wu C, Xu H and Fang L: MicroRNA-7 inhibits proliferation, migration and invasion of thyroid papillary cancer cells via targeting CKS2. Int J Oncol 49: 1531-1540, 2016

48. Lan Y, Zhang Y, Wang J, Lin C, Ittmann MM and Wang F: Aberrant expression of Cks1 and Cks2 contributes to prostate tumorigenesis by promoting proliferation and inhibiting programmed cell death. Int J Cancer 123: 543-551, 2008.

49. You H, Lin $\mathrm{H}$ and Zhang Z: CKS2 in human cancers: Clinical roles and current perspectives (Review). Mol Clin Oncol 3: 459-463, 2015.

50. Trempe JF, Sauvé V, Grenier K, Seirafi M, Tang MY, Ménade M, Al-Abdul-Wahid S, Krett J, Wong K, Kozlov G, et al: Structure of parkin reveals mechanisms for ubiquitin ligase activation. Science 340: 1451-1455, 2013.

51. Perez-Riverol Y, Csordas A, Bai J, Bernal-Llinares M, Hewapathirana S, Kundu DJ, Inuganti A, Griss J, Mayer G, Eisenacher M, et al: The PRIDE database and related tools and resources in 2019: Improving support for quantification data. Nucleic Acids Res 47: D442-D450, 2019. International (CC BY-NC-ND 4.0) License. 